\title{
Uncovering carbohydrate metabolism through a genotype-phenotype association study of 56 lactic acid bacteria genomes
}

\author{
Gemma Buron-Moles ${ }^{1}$ (D) Anna Chailyan ${ }^{1} \cdot \operatorname{Igor}^{\text {Dolejs }}{ }^{1} \cdot$ Jochen Forster $^{1} \cdot$ Marta Hanna Mikš $^{1,2,3}$
}

Received: 30 October 2018 / Revised: 14 February 2019 / Accepted: 14 February 2019 / Published online: 4 March 2019

(C) The Author(s) 2019

\begin{abstract}
Owing to their unique potential to ferment carbohydrates, both homo- and heterofermentative lactic acid bacteria (LAB) are widely used in the food industry. Deciphering the genetic basis that determine the LAB fermentation type, and hence carbohydrate utilization, is paramount to optimize LAB industrial processes. Deep sequencing of 24 LAB species and comparison with 32 publicly available genome sequences provided a comparative data set including five major LAB genera for further analysis. Phylogenomic reconstruction confirmed Leuconostoc and Pediococcus species as independently emerging from the Lactobacillus genus, within one of the three phylogenetic clades identified. These clades partially grouped LABs according to their fermentation types, suggesting that some metabolic capabilities were independently acquired during LAB evolution. In order to apply a genome-wide association study (GWAS) at the multigene family level, utilization of 49 carbohydrates was also profiled for these $56 \mathrm{LAB}$ species. GWAS results indicated that obligately heterofermentative species lack 1-phosphofructokinase, required for D-mannose degradation in the homofermentative pathway. Heterofermentative species were found to often contain the araBAD operon, involved in L-arabinose degradation, which is important for heterofermentation. Taken together, our results provide helpful insights into the genetic determinants of LAB carbohydrate metabolism, and opens for further experimental research, aiming at validating the role of these candidate genes for industrial applications.
\end{abstract}

Keywords Carbohydrate metabolism · Genome-wide association study · Genotype-phenotype association study · Lactic acid bacteria $\cdot$ Functional genomics $\cdot$ Microbial genomics

\section{Introduction}

With the increased accessibility of next-generation sequencing (NGS) and third-generation sequencing technologies,

Electronic supplementary material The online version of this article (https://doi.org/10.1007/s00253-019-09701-6) contains supplementary material, which is available to authorized users.

Gemma Buron-Moles

gemmaburonmoles@gmail.com

Jochen Forster

jochen.forster@carlsberg.com

1 Carlsberg Research Laboratory, J.C. Jacobsens Gade 4, 1799 Copenhagen V, Denmark

2 Faculty of Food Science, University of Warmia and Mazury, Plac Cieszyński 1, 10-726 Olsztyn, Poland

3 Present address: Glycom A/S, Kogle Allé 4, 2970 Hørsholm, Denmark including high-throughput sequencing (HTS) and wholegenome sequencing (WGS), the number of sequenced genomes has grown significantly, from approx. 31,000 in year 2014 to more than 160,000 prokaryotic genome sequences publicly available as for today (September 2018; http:// www.ncbi.nlm.nih.gov/genome/browse/). HTS technology opened a new window to study microorganism diversity on the, so far unknown, genetic scale. WGS also provided a fresh, broad insight into bacteria functionality at the genomic level, which has not been previously possible. Indeed, these emerging technologies unlocked the potential for microbial genome-wide association studies (GWAS), aiming at dissecting the genetic basis of known phenotypic traits (e.g., carbohydrate metabolism) (Dutilh et al. 2013). Understanding certain genotype-phenotype associations brings unprecedented opportunities for better utilization/exploration of technologically useful microorganisms, such as starter cultures in food technology (Wu et al. 2017), but also for the engineering of novel microbial organisms and consortia in synthetic biology 
applications (Freddolino et al. 2014). Bacterial evolution, epidemiology, pathogens' traceability during disease outbreaks, pathogenesis, antibiotic resistance, rapid detection, and food safety (Chen and Shapiro 2015; Brbić et al. 2016; Klemm and Dougan 2016; Deurenberg et al. 2017; Ruppé et al. 2017), exemplify areas where sequencing and GWAS revolutionized modern microbiology.

Lactic acid bacteria (LAB) is a naturally biodiverse, wellestablished group of microorganisms widely used in food industry and of well-documented impact on human health (Wu et al. 2017). LABs are "generally recognized as safe" (GRAS) in the USA and given the "Qualified Presumption of Safety" (QPS) status by the European Food Safety Authority (EFSA) (Zhang and Zhang 2014). They were isolated from various ecological niches, starting from the gastrointestinal tracts of humans, animals, and insects, through plant- and meat-based materials, to soil and water (Hammes and Hertel 2009). The ability acquired by LAB to metabolize several carbohydrates provided them competitive advantages to colonize numerous ecosystems. This variety of utilized substrates leverages a few metabolic pathways, which make LAB so unique and distinctive in terms of their fermentation potential. Based on the final fermentation product(s), LAB can be divided into two groups: homo- and hetero-fermentative, the latter being subdivided into facultatively and obligately fermentative species. Pediococcus, Lactococcus, Streptococcus, and selected Lactobacillus are considered obligate homofermentative, due to their ability to ferment only hexoses almost completely to lactic acid by the Embden-Meyerhof-Parnas (EMP) pathway, while pentoses are not degraded by all homofermenters (Pessione 2012). Facultatively heterofermentative LAB species, like Leuconostoc and certain Lactobacillus, degrade hexoses to lactic acid through EMP pathway, and can also metabolize pentoses and often gluconate as they possess both aldolase and phosphoketolase (Felis and Dellaglio 2007). The obligately heterofermentative LAB cannot utilize hexoses through the EMP pathway due to the lack of glycolytic enzyme fructose-1,6-bisphosphate aldolase. Instead, they degrade hexoses by the phosphogluconate pathway, producing not only lactic acid as the end product but also significant amounts of ethanol or acetic acid and carbon dioxide (Pessione 2012).

The industrial and technological relevance of LAB strains motivated extensive genomic studies, which have provided significant insight into their metabolism, physiology, and potential for new applications (Zhang and Zhang 2014; Bosma et al. 2017). Since 2001, when the first LAB genome was published (Bolotin et al. 2001), hundreds of LAB genomes have been sequenced and are publicly available at different assembly levels (Sun et al. 2015; Zheng et al. 2015; Wu et al. 2017; Salvetti et al. 2018). It has been demonstrated that combining phenotypic data and LAB strain-specific genetic information is an effective method for the assignment of unknown functions to specific genetic loci, especially those underlying important industrial traits, interaction with the host or niche adaptation (Siezen et al. 2011; Bayjanov et al. 2013; Ceapa et al. 2015). This has provided deeper understanding of LAB's carbohydrate metabolism and other phenotypic traits, which includes the discoveries of, e.g., arabinose and melibiose utilization genes in Lactococcus lactis of plant origin (Bayjanov et al. 2013), candidate genes that correlate with L-sorbose and $\alpha$-methyl-D-glucoside utilization in Lactobacillus rhamnosus (Ceapa et al. 2015), mannose-specific adhesin in Lactobacillus plantarum (Pretzer et al. 2005), or specific chromosomal orthologous groups (chrOGs) identified for Lactococcus lactis strain (separately for subspecies lactis and cremoris) (Siezen et al. 2011). However, in many LAB genomes, a number of carbohydrate-specific genes remain to be identified.

With the aim of better understanding carbohydrate utilization and fermentation, and ultimately help to optimize industrial processes, a genotype-phenotype association study was performed in a biodiverse group of LAB. This focused on Lactobacillus spp. potentially harboring industrial applications. Other four genera were added for comparative purposes, namely Lactococcus, Pediococcus, Leuconostoc, and Streptococcus. The genome of $24 \mathrm{LAB}$ species was sequenced and compared to 32 already available, in order to define multigene families across the $5 \mathrm{LAB}$ genera. Variation in multigene family size was then evaluated for association with 49 phenotypic traits, which characterize LAB carbohydrate metabolism. This analysis identified novel multigene families involved in carbohydrate degradation, as well as their relation with the respective LAB fermentation pathways.

\section{Materials and methods}

\section{Bacterial cultures and dataset}

A representative set of 50 type strains of $\mathrm{LAB}$ was selected to cover a bio-diverse group of microorganisms with potential industrial applications, mostly with GRAS/QPS status, different fermentation capacities, and strains' origins (Table 1). In addition, six in-house Lactococcus spp. isolates were also included (Carlsberg Research Laboratory, Copenhagen, Denmark). In total, 56 LAB strains have been examined comprising species from the following genera: Lactobacillus $(n=$ 42), Lactococcus $(n=8)$, Leuconostoc $(n=3)$, Pediococcus $(n=2)$, and Streptococcus $(n=1)$. The comparative panel of LAB strains included homofermentative $(n=31)$, heterofermentative $(n=4)$, facultatively heterofermentative $(n=12)$, and obligately heterofermentative $(n=9)$ representatives. The taxonomic status of Streptococcus salivarius spp. thermophilus has been contentious. Some authors have proposed that St. salivarius spp. thermophilus is not a subspecies 
Table 1 List of 56 strains of lactic acid bacteria (LAB) used in this study, including their origin and genome sequence availability

\begin{tabular}{|c|c|c|c|c|c|c|}
\hline \# & Taxon & Strain code & Origin & ${ }^{\mathrm{a}}$ Metabolism & $\begin{array}{l}{ }^{\mathrm{b}} \mathrm{GRAS} / \mathrm{QPS} \\
\text { status }\end{array}$ & NCBI accession \\
\hline $1 *$ & Lactococcus lactis ssp. lactis 1 & CRL 0001 & Cheese & Но & + & - \\
\hline $2 *$ & Lactococcus lactis ssp. lactis 2 & CRL 0002 & Cheese & Ho & + & - \\
\hline $3 *$ & Lactococcus lactis ssp. lactis 3 & CRL 0003 & Cheese & Но & + & - \\
\hline $4 *$ & Lactococcus lactis ssp. lactis 4 & CRL 0004 & Cheese & Но & + & - \\
\hline $5 *$ & Lactococcus lactis ssp. lactis 5 & CRL 0005 & Cheese & Но & + & - \\
\hline $6^{*}$ & Lactococcus lactis ssp. lactis 6 & CRL 0006 & Cheese & Ho & + & - \\
\hline $7 *$ & $\begin{array}{l}\text { Streptococcus salivarius ssp. } \\
\text { thermophilus }\end{array}$ & ATCC $19258^{\mathrm{T}}$ & Unknown & Ho & + & PRJNA433425 \\
\hline $8^{*}$ & Pediococcus pentosaceus & ATCC $33316^{\mathrm{T}}$ & Unknown & Но & + & PRJNA434256 \\
\hline $9 *$ & Lactococcus lactis ssp. lactis & ATCC $19435^{\mathrm{T}}$ & Unknown & Ho & + & PRJNA434373 \\
\hline $10 *$ & Lactococcus lactis ssp. cremoris & ATCC $19257^{\mathrm{T}}$ & Unknown & Ho & + & PRJNA434374 \\
\hline $11 *$ & Lactobacillus sakei ssp. sakei & ATCC $15521^{\mathrm{T}}$ & "Moto" starter of sake & $\mathrm{FHe}$ & + & PRJNA434375 \\
\hline $12 *$ & Lactobacillus amylolyticus & DSM11664 ${ }^{\mathrm{T}}$ & Acidified beer wort & Ho & + & PRJNA434376 \\
\hline $13^{*}$ & $\begin{array}{l}\text { Lactobacillus delbrueckii ssp. } \\
\text { jakobsenii }\end{array}$ & DSM $26046^{\mathrm{T}}$ & $\begin{array}{l}\text { Malted sorghum wort, } \\
\text { African dolo wort }\end{array}$ & Но & + & PRJNA434378 \\
\hline $14 *$ & Leuconostoc citreum & ATCC $49370^{\mathrm{T}}$ & Honey dew of rye ear & $\mathrm{He}$ & + & PRJNA434381 \\
\hline $15^{*}$ & Leuconostoc fallax & $\begin{array}{l}\text { ATCC } \\
\quad 700006^{\mathrm{T}}\end{array}$ & Sauerkraut & $\mathrm{He}$ & - & PRJNA434383 \\
\hline $16^{*}$ & Lactobacillus silagei & DSM $27022^{\mathrm{T}}$ & $\begin{array}{l}\text { Orchardgrass (Dactylis } \\
\text { glomerata L.) silage }\end{array}$ & $\mathrm{He}$ & - & PRJNA434387 \\
\hline $17 *$ & $\begin{array}{l}\text { Lactobacillus paracasei ssp. } \\
\quad \text { paracasei }\end{array}$ & ATCC $25302^{\mathrm{T}}$ & Unknown & $\mathrm{FHe}$ & + & PRJNA434388 \\
\hline $18^{*}$ & Lactobacillus parakefiri & DSM $10551^{\mathrm{T}}$ & Kefir grain & $\mathrm{OHe}$ & - & PRJNA434396 \\
\hline $19 *$ & Lactobacillus pentosus & ATCC $8041^{\mathrm{T}}$ & Unknown & $\mathrm{FHe}$ & + & PRJNA434401 \\
\hline $20 *$ & Lactobacillus farciminis & ATCC $29644^{\mathrm{T}}$ & Sausage & Ho & + & PRJNA434405 \\
\hline $21 *$ & Lactobacillus malefermentans & ATCC $49373^{\mathrm{T}}$ & Beer & $\mathrm{OHe}$ & - & PRJNA434406 \\
\hline $22 *$ & Lactobacillus buchneri & $\operatorname{ATCC} 4005^{\mathrm{T}}$ & Tomato pulp & $\mathrm{OHe}$ & + & PRJNA434409 \\
\hline $23 *$ & Lactobacillus pasteurii & DSM $23907^{\mathrm{T}}$ & Beer contaminant & Ho & + & PRJNA434410 \\
\hline $24 *$ & Lactobacillus hilgardii & ATCC $8290^{\mathrm{T}}$ & Wine & $\mathrm{OHe}$ & + & PRJNA434413 \\
\hline 25 & $\begin{array}{l}\text { Lactobacillus delbrueckii } \\
\text { ssp. bulgaricus }\end{array}$ & ATCC $11842^{\mathrm{T}}$ & Yogurt & Ho & + & NC_008054 \\
\hline 26 & $\begin{array}{l}\text { Lactobacillus delbrueckii } \\
\text { ssp. delbrueckii }\end{array}$ & ATCC $9649^{\mathrm{T}}$ & Sour grain mash & Ho & + & NZ_AZCR00000000 \\
\hline 27 & $\begin{array}{l}\text { Lactobacillus delbrueckii } \\
\text { ssp. lactis }\end{array}$ & ATCC $12315^{\mathrm{T}}$ & Emmental cheese & Ho & + & NZ_AZDE01000001 \\
\hline 28 & Lactobacillus helveticus & ATCC $15009^{\mathrm{T}}$ & Emmental cheese & Но & + & NZ_AZEK01000001 \\
\hline 29 & Lactobacillus dextrinicus & ATCC $33087^{\mathrm{T}}$ & Silage & Ho & + & NZ_AYYK01000004 \\
\hline 30 & Lactobacillus mali & ATCC $27053^{\mathrm{T}}$ & $\begin{array}{l}\text { Apple juice from cider } \\
\text { press }\end{array}$ & Но & + & NZ_AYYH01000001 \\
\hline 31 & Lactobacillus acidophilus & ATCC $4356^{\mathrm{T}}$ & $\begin{array}{l}\text { Gastrointestinal tract } \\
\text { and mouth }\end{array}$ & Ho & + & NZ_AZCS01000001 \\
\hline 32 & Pediococcus acidilactici & ATCC $8042^{\mathrm{T}}$ & Unknown & Но & + & NZ_GL397067 \\
\hline 33 & Lactobacillus nagelii & $\begin{array}{l}\text { ATCC } \\
\quad 700692^{\mathrm{T}}\end{array}$ & Partially fermented wine & Но & - & NZ_AZEV01000035 \\
\hline 34 & Lactobacillus salivarius & ATCC $11741^{\mathrm{T}}$ & Saliva & Но & + & NZ_GG693223 \\
\hline 35 & Lactobacillus fermentum & ATCC $14931^{\mathrm{T}}$ & Fermented beets & $\mathrm{OHe}$ & + & NZ_GG669900 \\
\hline 36 & Lactobacillus reuteri & ATCC $23272^{\mathrm{T}}$ & Intestine of adult & $\mathrm{OHe}$ & + & NC_009513.1 \\
\hline 37 & $\begin{array}{l}\text { Lactobacillus sakei } \\
\quad \text { ssp. carnosus }\end{array}$ & DSM $15831^{\mathrm{T}}$ & Fermented meat product & $\mathrm{FHe}$ & + & NZ_AZFG01000049 \\
\hline 38 & $\begin{array}{l}\text { Lactobacillus } \\
\quad \text { sanfranciscensis }\end{array}$ & ATCC $27651^{\mathrm{T}}$ & San Francisco sourdough & $\mathrm{OHe}$ & + & NZ_AYYM01000001 \\
\hline 39 & Lactobacillus vini & DSM $20605^{\mathrm{T}}$ & $\begin{array}{l}\text { Grape must, fermenting } \\
\text { at high temperature }\end{array}$ & FHe & - & NZ_AYYX01000001 \\
\hline 40 & Lactobacillus amylovorus & ATCC $33620^{\mathrm{T}}$ & $\begin{array}{l}\text { Cattle waste-corn fermenta- } \\
\text { tion }\end{array}$ & Но & + & NZ_AZCM01000001 \\
\hline 41 & Lactobacillus composti & DSM $18527^{\mathrm{T}}$ & $\begin{array}{l}\text { Composting material of } \\
\text { distilled shochu residue }\end{array}$ & $\mathrm{FHe}$ & - & NZ_AZGA01000088 \\
\hline 42 & Lactobacillus farraginis & DSM $18382^{\mathrm{T}}$ & $\begin{array}{l}\text { Composting material } \\
\text { of distilled shochu residue }\end{array}$ & FHe & - & NZ_AZFY01000034 \\
\hline 43 & $\begin{array}{l}\text { Leuconostoc mesenteroides } \\
\text { ssp. cremoris }\end{array}$ & ATCC $19254^{\mathrm{T}}$ & Hansen's dried starter powder & $\mathrm{He}$ & + & NZ_GG693383 \\
\hline 44 & Lactobacillus uvarum & DSM $19971^{\mathrm{T}}$ & Must of Bobal grape variety & Но & - & NZ AZEG01000001 \\
\hline 45 & Lactobacillus oeni & DSM $19972^{\mathrm{T}}$ & Bobal wine & Ho & - & NZ_AZEH01000039 \\
\hline 46 & Lactobacillus zeae & ATCC $15820^{\mathrm{T}}$ & Corn steep liquor & $\mathrm{FHe}$ & + & NZ_AZCT01000001 \\
\hline
\end{tabular}


Table 1 (continued)

\begin{tabular}{|c|c|c|c|c|c|c|}
\hline \# & Taxon & Strain code & Origin & ${ }^{\mathrm{a}}$ Metabolism & $\begin{array}{l}{ }^{\mathrm{b}} \mathrm{GRAS} / \mathrm{QPS} \\
\text { status }\end{array}$ & NCBI accession \\
\hline 47 & Lactobacillus kefiri & ATCC $35411^{\mathrm{T}}$ & efir grain & $\mathrm{OHe}$ & - & NZ_AYYV01000004 \\
\hline 48 & Lactobacillus gasseri & ATCC $33323^{\mathrm{T}}$ & Human & Но & + & $\mathrm{NC} 008530.1$ \\
\hline 49 & Lactobacillus alimentarius & ATCC $29643^{\mathrm{T}}$ & Marinated fish product & $\mathrm{FHe}$ & + & $\mathrm{NZ}_{\overline{-}}^{-}$ \\
\hline 50 & Lactobacillus gallinarum & ATCC $33199^{\mathrm{T}}$ & Chicken crop & Но & + & NZ_AZEL01000047 \\
\hline 51 & Lactobacillus johnsonii & ATCC $33200^{\mathrm{T}}$ & Human blood & Но & + & NZ_GG670120 \\
\hline 52 & $\begin{array}{l}\text { Lactobacillus plantarum ssp. } \\
\text { plantarum }\end{array}$ & ATCC $14917^{\mathrm{T}}$ & Pickled cabbage & FHe & + & NZ_GL379762 \\
\hline 53 & Lactobacillus casei & ATCC $393^{\mathrm{T}}$ & Cheese & $\mathrm{FHe}$ & + & NZ_AZCO01000001 \\
\hline 54 & Lactobacillus curvatus & ATCC $25601^{\mathrm{T}}$ & Milk & $\mathrm{FHe}$ & + & NZ_AZDL01000001 \\
\hline 55 & Lactobacillus brevis & ATCC $14869^{\mathrm{T}}$ & Feces & $\mathrm{OHe}$ & + & NZ_AZCP01000001 \\
\hline 56 & $\begin{array}{l}\text { Lactobacillus coryniformis ssp. } \\
\text { coryniformis }\end{array}$ & $\operatorname{ATCC} 25602^{\mathrm{T}}$ & Silage & $\mathrm{FHe}$ & - & NZ_AZCN01000001 \\
\hline
\end{tabular}

*Newly sequenced bacterial strains and de novo assembled genomes; ${ }^{\mathrm{T}}$ type strain

${ }^{a}$ LAB metabolism according to Felis and Dellaglio (2007): $\mathrm{Ho}$ homofermentative, $\mathrm{He}$ heterofementative, $\mathrm{FHe}$ facultatively heterofermentative, $\mathrm{OHe}$ obligately heterofermentative

${ }^{\mathrm{b}}$ GRAS/QPS: generally recognized as safe/qualified presumption of safety

of St. salivarius, but a separate species (Facklam 2002). Hereafter, ATCC 19258 is referred to as St. salivarius spp. thermophilus, for consistency with the name used by the provider. Type strains were purchased from American Type Culture Collection (ATCC, Manassas, VA, USA), LeibnizInstitut DSMZ-Deutsche Sammlung von Mikroorganismen und Zellkulturen GmbH (DSMZ, Braunschweig, Germany), Statens Serum Institut (SSI, Copenhagen, Denmark), and Microbiologics (MicroBioLogics, St. Cloud, MN, USA). All isolates were maintained as frozen stocks in $50 \%(w / w)$ glycerol tubes at $-80{ }^{\circ} \mathrm{C}$. Subsequently, the strains were activated prior to the experiments by double sub-culturing (of an aliquot of 100ul) in $9 \mathrm{ml}$ of de Man Rogosa Sharp (MRS), or M17 (Oxoid, Basingstoke, Hampshire, England) supplemented with $0.5 \%$ glucose (Merck, Darmstadt, Germany), and incubated aerobically at optimal temperature for 24-72 h.

The dataset of 32 complete genome sequences of LAB strains (at least at the scaffold level) was obtained from the NCBI (The National Center for Biotechnology Information Microbial Genomes database) (http:/www.ncbi.nlm.nih.gov/ genome/browse/) on 15 August 2016. The remaining 24 LAB strains, for which sequences were not publicly available or their assemblies were incomplete (i.e., deposited only at the contig level), were newly sequenced using Illumina HiSeq technology.

\section{Phenotypic characterization}

The fermentation patterns were characterized with a standardized system, API 50 CHL (BioMérieux, Marcy l'Etoile, France) consisting of 50 biochemical tests for the study of bacterial carbohydrate metabolism. API $50 \mathrm{CH}$ was used in conjunction with API $50 \mathrm{CHL}$ medium according to the manufacturer's instructions. Briefly, active cultures of bacterial isolates or type strains were washed twice with sterile physiological saline $(0.9 \% \mathrm{w} / \mathrm{v}, \mathrm{NaCl})$ and pellets were resuspended in API 50 CHL medium (API systems, BioMérieux). Homogenized cells' suspensions were transferred into 50-wells of the API $50 \mathrm{CH}$ strips using sterile Pasteur pipettes. All wells were overlaid with sterile mineral oil (Sigma, St. Louis, MO, USA) to effect anaerobiosis. Strips were moistened and covered as recommended by the manufacturer and incubated at optimal temperature $\left(30\right.$ or $\left.37^{\circ} \mathrm{C}\right)$. Changes in well color were monitored throughout the experiment, recorded after two, and verified after 10 days. For computing purposes, the results were translated to binary code, "one" for positive reaction, "zero" for negative results for all tested strains.

\section{Whole-genome sequencing and assembly}

In this study, $24 \mathrm{LAB}$ genomes have been sequenced using Illumina HiSeq 4000 technology. A paired-end library was constructed, and PE150 (HiSeq) sequencing targeting 100fold coverage per each sample has been performed. Raw Illumina sequencing reads were trimmed using the CLC Genomics Workbench v 9.0 (https://www. qiagenbioinformatics.com/products/clc-genomicsworkbench) with base calling error probability cutoff of $p=0$. 05 (equivalent to Phred quality score 13). Sequences shorter than $1 / 3$ of the original read length, those containing ambiguous nucleotides, and all adapter sequences were removed. The bacterial genomes were de novo assembled using Abyss assembler (Simpson et al. 2009). For each bacterium, 12 assemblies were constructed using different $K$-mers $(20,32$, $40,50,60,65,70,75,80,85,90,96)$. Subsequently, 
contigs assembled for each LAB strain were evaluated with in-house scripts available upon request, retaining the best assembly for each strain, according to a number of criteria calculated by QUAST (Gurevich et al. 2013). The assembly having the lowest overall rank, calculated as the sum of the individual ranks for N50, genome length, and total number of contigs, was selected as the best. The overall report on N50 of the best assembly for each bacterium is shown in Fig. 1.

\section{Nucleotide sequence accession numbers}

The newly sequenced genomes of 18 LAB strains, together with the corresponding gene annotations, were deposited in the GenBank database with the accession codes listed in Table 1.

\section{Gene prediction and functional annotation}

The genome sequences were annotated in the following steps. Firstly, ab initio gene prediction of protein-coding genes for newly sequenced LAB genomes was performed using Prodigal (ver.2.6.1) software (Hyatt et al. 2010). The gff files together with protein sequence predictions were saved for each bacterium and were added to the remaining 32 bacteria for which the protein sequences have been downloaded from NCBI. The identified proteins were searched against UniFam_Prok database (159,895 families) using HMMER (ver.3.1) software (Chai et al. 2014). Top matches of proteins passing the whole-sequence $E$ value cutoff $(<1 \mathrm{e}-4)$ and coverage cutoff (aligned regions cover at least $50 \%$ of both the matched HMM and the query protein) were selected. Proteins were then annotated with the function of their best-matched UniFam families. For each genome, the proportion of gene ontology (GO) terms was provided by the CateGOrizer software (ver.3.218) (Hu et al. 2008), according to GO_slim2 annotations and assuming the "consolidated single occurrences count" option.

\section{Inference of orthologous gene groups}

The proteins of the 56 bacteria were clustered into orthologous groups (OGs) using OrthoFinder (Emms and Kelly 2015). First, all-versus-all searches were performed using the BLASTP algorithm (Altschul et al. 1990), with an $E$ value threshold of $10^{-3}$. This relaxed cutoff avoids discarding putative good hits for very short sequences. At the second step, allvs-all BLAST hits were modeled for each pairwise comparison between species, revealing and removing the gene similarity dependency on gene length and phylogenetic distance. Subsequently, the information from the reciprocal best lengthnormalized hit (RBNH) was used to define the lowest sequence similarity that delimits putative homologous genes. On the next step, the putative homologous gene-pairs were identified and connected in the orthogroup graph with weights

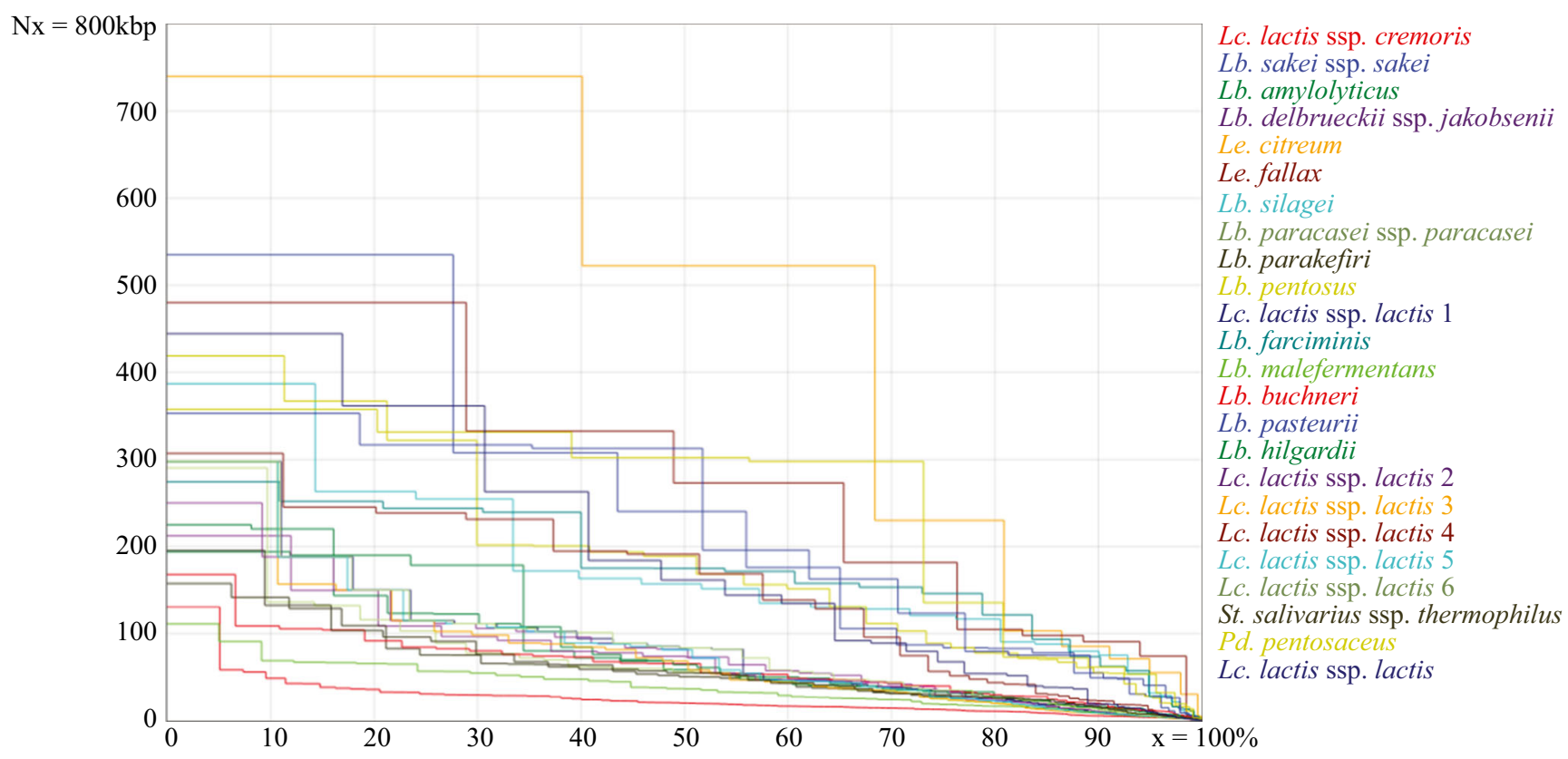

Fig. 1 Cumulative length of contigs (Nx), as reported by QUAST. In the $x$-axis, $50 \%$ measures the N50 across the 24 new assemblies, which are colorcoded as depicted in figure legend. Assemblies with higher $\mathrm{Nx}$ values are more contiguous 
given by the normalized BLAST bit scores. As final OrthoFinder step, genes were clustered into orthogroups using Markov cluster algorithm (MCL).

\section{Phylogenetic tree}

In order to build the phylogenetic tree, 219 ortholog groups were defined by OrthoFinder (Emms and Kelly 2015) as containing a single-copy in each of the 56 LAB species (i.e., 1:1 orthologs). For each of the 219 ortholog groups, corresponding protein sequences were aligned, using MAFFT v7.310 with default parameters (Katoh and Standley 2013). The resulting 219 alignments were concatenated, yielding a multiple alignment with 74,379 positions in total. RAxML v8.2.10 (Stamatakis 2014) automatically identified LG as best-fit model for protein evolution, prior to inferring the maximum likelihood (ML) phylogenetic tree. A hundred bootstrap replicates were run to assess node support. The tree was manually rooted, assuming St. salivarius ssp. thermophilus and Lc. lactis group as outgroup species, in line with their basal phylogenetic placement inferred by previous phylogenetic analyses (Makarova et al. 2006; Makarova and Koonin 2007; Salvetti et al. 2013; Sun et al. 2015).

\section{Association of phenotypic data to genomic data}

In order to carry out the association study, two data matrices were generated. Matrix A contained the protein count for each of the 56 species, in each of the 5932 orthogroups. Matrix B contained categorical phenotypes on 49 carbohydrate substrate utilization, for each of the 56 species. For each of these substrates, the probability that an orthogroup is associated with its metabolization was estimated through a nonparametric Wilcoxon rank sum test (Whitley and Ball 2002); i.e., assessing whether the number of genes within the focal orthogroup differed between species able and unable to metabolize the substrate. This amounted to a total of 290,668 statistical tests, which were adjusted for multiple testing using two different methods: Bonferroni (Bland and Altman 1995) and false discovery rate (FDR) (Benjamini and Hochberg 1995), at two different thresholds, 0.05 and 0.01 .

The R packages "gplots" (Warnes et al. 2016), "devtools" (Hadley et al. 2017), "RcolorBrewer" (Neuwirth 2014), together with a customized heatmap.3 source code (Zhao et al. 2015) for hierarchical clustering based on Euclidean distance and a complete-linkage metric, have been used for results visualization (www. R-project.org). The functional annotations generated with UniFam_Prok were incorporated into the final heatmap, thus facilitating the biological interpretation of the results.

\section{Results}

\section{Genome sequencing and assembly}

In this study, the 56 LAB genomes were compared, of which 32 were obtained from NCBI database on 15th August 2016. For the remaining $24 \mathrm{LAB}$ strains, whole-genome sequencing (WGS) and de novo assembly were performed, including representatives of the following species: Lactobacillus ( $L b ; n=$ 12), Lactococcus (Lc;n=8), Leuconostoc (Le; $n=2)$, Pediococcus $(P d ; n=1)$, and Streptococcus $(S t ; n=1)$ (Table 1). The sequences of 6 strains (out of 24) were not released owing to commercial reasons. More importantly, among these 24 newly sequenced genomes, 2 type strains, St. salivarius ssp. thermophilus (DSM 20617) and Le. citreum (DSM 5577), were unavailable at NCBI at the time of manuscript preparation (Table 1). Finally, these 24 sequenced genomes also included 16 strains for which the assemblies were available, however, fragmented in multiple contigs.

After processing the HiSeq 4000 sequencing reads, de novo assemblies $(n=24)$ amounted to total lengths between $1.6 \mathrm{Mb}$ for Lb. amylolyticus and $3.7 \mathrm{Mb}$ for Lb. pentosus. Strains with greater genome sizes exhibited elevated GC content, a trend only broken by the genomes with most extreme GC contents, namely the two Lc. lactis $(<36.02 \%), L b$. farciminis $(36.4 \%)$ and Lb. delbrueckii ssp. jakobsenii $(50.1 \%)$ (Supplementary Table S1). The total number of contigs ranged from 10 for Le. citreum to 208 for Lc. lactis ssp. cremoris, showing the maximum and minimum N50 values of $522.10 \mathrm{~kb}$ and $20.25 \mathrm{~kb}$, respectively (Fig. 1). The fraction of missing nucleotides was limited $(<0.02 \%)$.

According to these summary statistics (Supplementary Table S1), the assembly of the 16 re-sequenced LAB strains substantially improved, having now less and often longer contigs. For 6 strains (out of 16), the N50 remained unchanged, whereas it was considerably increased for the other 10 genomes, up to 3.93-fold in Lb. pentosus. Greater N50 was reflected in an increased contiguity in the respective assemblies. Concomitantly, the total number of contigs was reduced for all 16 strains, especially for the Lb. parakefiri assembly, which was fragmented in 506 contigs and here is represented by only 101 (Supplementary Table S1). Altogether, this genomic set not only constitutes a substantial extension and improvement to the LAB genomes, but has also been consistently generated with the same methodology, minimizing potential biases, and representing therefore a suitable data set for comparative genomic studies.

\section{Gene prediction and functional annotation}

$\mathrm{Ab}$ initio gene prediction was conducted for the 24 new genome assemblies, yielding a minimum and maximum of protein-coding genes between 1648 in Le. fallax and 3366 in 
Lb. pentosus. This range is comparable to that observed for the 32 genome assemblies downloaded from NCBI, which ranges from 1175 for Lb. sanfranciscensis to 3196 in Lb. composti. Regarding the 16 re-sequenced LAB strains for which the assembly was improved, the number of annotated genes increased, as expected (Supplementary Table S1). Indeed, genes previously disrupted in different contigs were challenging to identify, but were discovered in this study due to more contiguous assemblies. Gene mis-identification due to assembly fragmentation is expected to be particularly important in LAB genomes, since these are generally compact, with approximately one gene per kb (Supplementary Table S1).

Leveraging UniFam functional annotations, gene ontology (GO) terms were assigned to the clear majority of proteincoding genes identified. This percentage ranged from $57 \%$ in St. salivarius ssp. thermophilus to $82 \%$ in Lb. oeni, an averaged $70 \%$ across 56 LAB strains. Each functionallyannotated gene was characterized by a mean of 3.7 GO terms. Within each LAB strain, the distribution of GO terms was similar, as reflected by the pie charts of four species that exhibit similar GO proportions despite belonging to two different phylogenetic clades, and having different fermentation types (Supplementary Fig. S1). Among the GO terms present in all 56 LAB strains, catabolism and carbohydrate metabolism were the two functional categories showing the highest coefficient of variation (1.0258 and 1.0231, respectively). Interestingly, this indicates that the relative abundance of genes regulating carbohydrate metabolism substantially differs across the 56 LAB species.

\section{Ortholog groups of genes}

Across the 56 LAB genomes, 5932 multigene families have been identified, encompassing the $96.2 \%$ of the 123,255 predicted genes. Only $4700(3.8 \%)$ of the total genes were not assigned to any multigene family, supporting consistent gene predictions across the 56 LAB genomes. St. salivarius ssp. thermophilus showed the lowest fraction of genes $(82.9 \%)$ assigned to multigene families. For the remaining species, the proportion was $91.7 \%$ or above, even reaching $100 \%$ for the species Lc. lactis ssp. lactis 6. There were 315 multigene families identified in all 56 LAB species, of which 219 contained exactly a single gene copy per species. The results are presented in the histogram (Fig. 2) summarizing the size of the ortholog groups, which peaks at 56 genes. This peak is in line with some ortholog groups conserved as single copy in the 56 LAB genomes; i.e., each species has a single gene in each family, reflecting important genes that cannot be lost, known as the core genome (Supplementary Table S2). These 219 families represent, therefore, a minimal core genome, and reveal high turnover of gene gains and losses for the rest of the families. For example, in OG0000028, corresponding to a transposase multigene family, the number of genes ranges from 0 in the majority of species to 73 in St. salivarius ssp. thermophilus type strain examined in this study.

\section{Phylogenetic tree}

The phylogenetic relationship between the 56 LAB strains was inferred by maximum Likelihood (ML), from the concatenated alignments of the 219 proteins that constitute their core gene set (Fig. 3). Hence, branch lengths represent the number of amino acid substitutions per site. The strains of both St. salivarius ssp. thermophilus and Lc. lactis group were considered as outgroups, in order to root the tree. All major nodes in the tree are well-supported by high bootstrap values, demonstrating that intergroup relationships are reflected accurately.

The phylogeny clusters LAB according to their genera, separating Leuconostoc and Pediococcus within Lactobacillus diversity. These genera embedded in three major phylogenetic clades, namely (A), (B), and (C) (Fig. 3). Clade A corresponds to the species forced to be outgroup, which includes strains of the Lc. lactis group and St. salivarius ssp. thermophilus. Their basal phylogenetic placement as outgroup is robustly supported by previous studies (Makarova et al. 2006; Makarova and Koonin 2007; Salvetti et al. 2013; Sun et al. 2015). Clade B contains all possible metabolic profiles, and is comprised of three different genera, with Pediococcus and Leuconostoc emerging as two independent groups within Lactobacillus species. Finally, clade C only contains facultatively heterofermentative and homofermentative strains (Fig. 3).

With a few exceptions, these major phylogenetic clades do not show clear differences, in terms of distinctive GC content, genome size, or number of proteins (Fig. 3). The highest GC content was observed in the obligately heterofermentative species $L b$. fermentum (52.6\%), and in the clade formed by homofermentative species Lb. delbrueckii ssp. jakobsenii, bulgaricus, delbrueckii, and lactis (approx. 50\% each). Another group with high GC content is the one formed by the facultatively heterofermentative species $L b$. zeae, $L b$. casei, and Lb. paracasei ssp. paracasei $(47.7 \%, 46.5 \%$, and $46.5 \%$, respectively). Notably, the last two groups belong to the major clade $\mathrm{C}$. The group with the highest genome size is the one formed by the facultatively heterofermentative species Lb. pentosus $(3.7 \mathrm{Mb})$ and $L b$. plantarum ssp. plantarum (3.2 Mb), followed by the facultatively heterofermentative species $L b$. composti (3.5 Mb), Lb. zeae (3.1 Mb), and $L b$. paracasei ssp. paracasei $(3.0 \mathrm{Mb})$. The two strains with larger genomes $L b$. pentosus $(3.7 \mathrm{Mb})$ and $L b$. composti $(3.5 \mathrm{Mb})$, both facultatively heterofermentative species, also have the highest number of predicted protein-coding genes (3366 and 3196, respectively) (Fig. 3).

Mapping the carbohydrate fermentation patterns of the 56 LAB strains revealed that some phylogenetically-related 
species showed diverse fermentative capabilities. More specifically, four pairs of closely clustered LAB species: $L b$. nagelii-Lb. vini; Lb. silagei-Lb. malefermentans; $L b$. hilgardii-Lb. farraginis; Lb. alimentarius-Lb. farciminis, are known to form different end products of lactic acid metabolic pathway (Felis and Dellaglio 2007). For example, even though $L b$. alimentarius and $L b$. farciminis showed relatively high sequence similarity, currently $L b$. alimentarius is classified as facultatively heterofermentative, while $L b$. farciminis as homofermentative. Similarly, the homofermentative LAB $L b$. nagelii clustered in the phylogenetic tree with the facultatively heterofermentative $L b$. vini.

\section{Genotype-phenotype association study of LAB}

\section{Phenotypic characterization of LAB}

The capability of 56 LAB strains to metabolize 49 carbohydrate substrates (using API $50 \mathrm{CHL}$ biochemical assay) has been evaluated. The fermentation profiles of the carbohydrates demonstrated significant phenotypic diversity among tested LAB. For descriptive purposes, LAB species are hereafter defined through their representative type strains. In this regard, it is worth cautioning that some degree of strain-tostrain variation could exist within the same species (Siezen et al. 2010; Bayjanov et al. 2013; Smokvina et al. 2013; Ceapa et al. 2015), as reflected by the phenotypic profiles of Lc. lactis ssp. lactis strains (Fig. 4). In addition, 49 carbohydrate substrates have been grouped into monosaccharides, disaccharides, polysaccharides, polyols, and salts (Fig. 4).

Monosaccharides are the most basic, fundamental units and can be classified according to their number of carbon atoms. Among common carbon sources classified as hexoses (C6), Dglucose is the only that can be degraded by all the 56 strains. Similarly, with a few exceptions in each phylogenetic clade, the LAB studied can metabolize D-galactose, D-fructose, and D-mannose. Interestingly, all strains in clades $\mathrm{A}$ and $\mathrm{C}$ were able to degrade D-fructose. Other hexoses such as D-tagatose, D-fucose, and L-fucose can be degraded by less LAB strains, if any. For example, D-tagatose, a stereoisomer of fructose (ketohexose), can only be degraded by a few LAB members of the clades B and C, basically Lactobacillus and Pediococcus strains. While only $L b$. zeae and $L b$. composti strains out of the 56 can degrade L-fucose, D-fucose cannot be degraded by any of our LAB studied (Fig. 4). Among the carbon sources classified as pentoses (C5), D-arabinose, Larabinose, D-ribose, D-xylose, and L-xylose are included. Only $L b$. zeae can degrade D-arabinose, whereas different members in clades B and C, especially in clade B, were able to metabolize L-arabinose. Other pentoses such as D-ribose and D-xylose cannot be degraded by Leuconostoc strains. As L-xylose, D-lyxose, a stereoisomer of ribose (aldopentose),

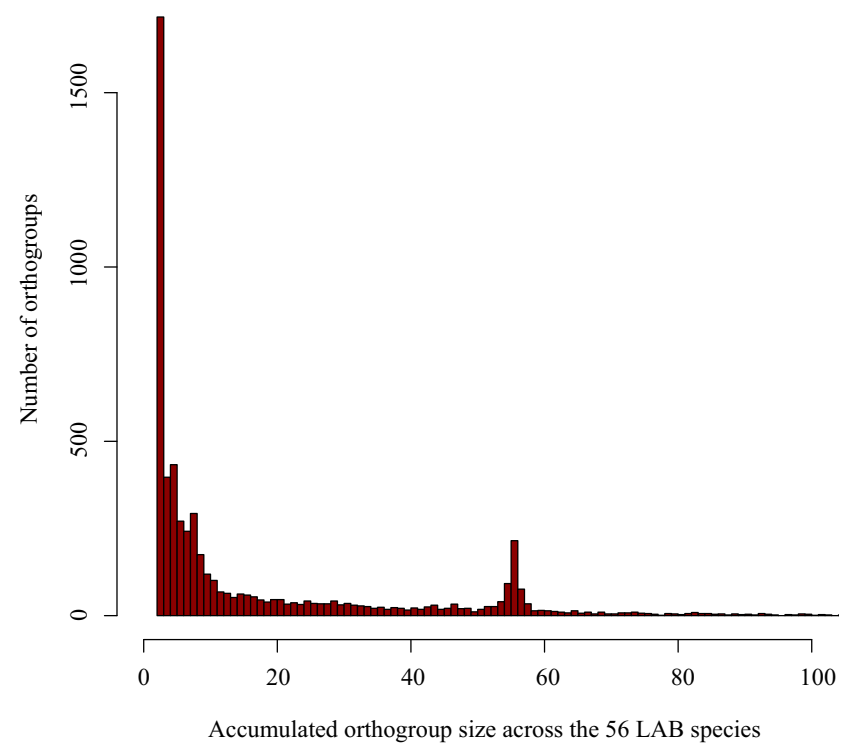

Fig. 2 Histogram summarizing the cumulative number of genes within orthogroups, across the $56 \mathrm{LAB}$ strains. For example, there are more than 1500 orthogroups (out of 5932) including 2 genes across the 56 LAB, implying either 2 genes in 1 species, or 1 gene in 2 species. Note the histogram secondarily peaks at 56 , an excess reflecting the presence of the "core genome". This is, orthogroups with a single gene copy per strain, thereby 56 in total per orthogroup

cannot be metabolized by any of the LAB tested in this study (Fig. 4).

Calculating the percentage of monosaccharides showed that none of the strains of clade A degraded L-arabinose, Lsorbose, L-rhamnose, D-tagatose, and methyl- $\alpha \mathrm{D}-$ glucopyranoside, in contrast to clades $\mathrm{B}$ and $\mathrm{C}$, where these monosaccharides are degraded by several strains (Fig. 4).

Disaccharides-carbohydrates composed of two monosaccharides joined by a glycosidic bond, such as D-maltose, Dlactose, and D-saccharose (sucrose), are common energy sources for bacterial cells. Almost all strains were able to ferment D-maltose, and those are distributed through the three major phylogenetic clades (Fig. 4). In general, all the strains can ferment D-lactose and D-saccharose with some exceptions. For example, Leuconostoc cannot degrade D-lactose and Lactococcus strains cannot utilize D-saccharose. Other disaccharides found in API strips were amygdalin, arbutin, esculin/ ferric citrate, salicin, D-cellobiose, D-melibiose, and D-trehalose. The utilization of these disaccharides implies the presence of various hydrolytic enzymes that enable them to break down the substrate, such as $\beta$-glucosidase (EC 3.2.1.21) for salicin, cellobiose and melibiose or $\beta$-amylase (EC 3.2.1.28) for trehalose.

The percentage of disaccharides utilized per clade showed that D-melibiose and D-turanose are degraded by some strains of clades B and C, but by none of clade A (Fig. 4).

Polysaccharides are carbohydrates composed of at least three monosaccharide units (e.g., D-melezitose, D-raffinose) or their longer linear or branched polymers (e.g., inulin or 

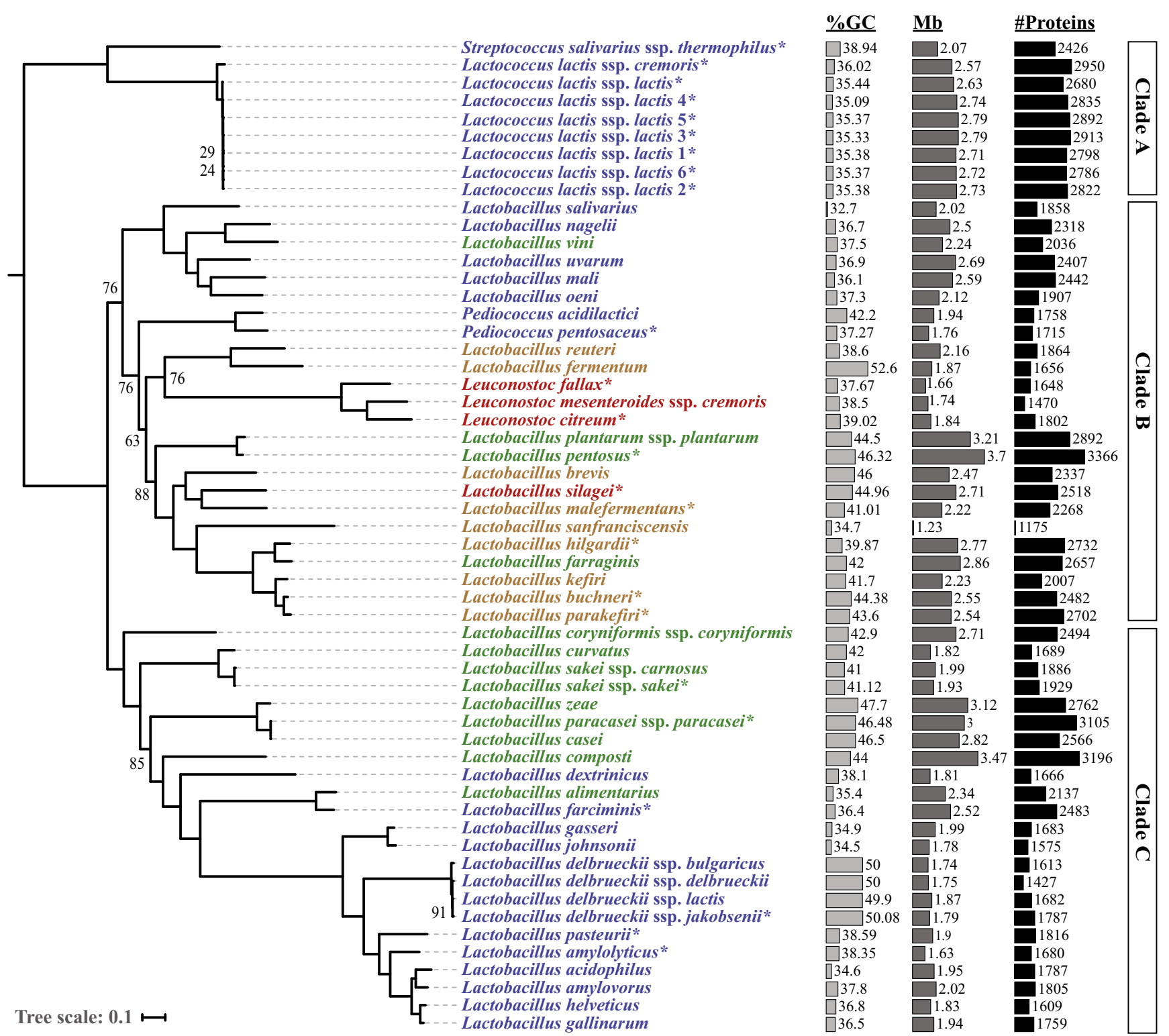

Fig. 3 Phylogenetic tree based on the concatenate of 219 proteins from 56 LAB strains, including 24 de novo sequenced (*). LAB strains were color-coded according to Felis and Dellaglio (2007), by fermentation endproduct (historically, type of fermentation): homofermentative (blue), heterofermentative (red), facultatively heterofermentative (green), and obligately heterofermentative (brown). Tree scale is given in amino acid substitutions per site. Only bootstrap values lower than 100 are shown. The GC content (\%GC), genome size (Mb), and the number of predicted proteins (\#Proteins) are presented as barplots. Text boxes on the right delineate the three major clades $(\mathrm{A}, \mathrm{B}, \mathrm{C})$ starch and glycogen, respectively) bound with glycosidic linkages. The trisaccharide D-melezitose can be fermented by a few LAB of the clades B and C, basically Lactobacillus strains. In clade $\mathrm{B}$, this corresponds to $L b$. plantarum ssp. plantarum, Lb. farraginis, Lb. buchneri, and Lb parakefiri, whereas in clade $\mathrm{C}$ to $L b$. zeae, $L b$. paracasei ssp. paracasei, $L b$. casei, and Lb. composti (Fig. 4). The utilization of melezitose implies, for example, the presence of the hydrolytic enzymes $\beta$-fructofuranosidase (EC 3.2.1.26) and $\alpha$ glucosidase (EC 3.2.1.20) to break down the substrate. Trisaccharide D-raffinose, composed of galactose, glucose, and fructose, was utilized by three strains of clade $\mathrm{C}$, and even more strains of clade $\mathrm{B}$, including Pediococcus pentosaceus and Lactobacillus strains. Raffinose can be hydrolyzed to Dgalactose and sucrose by the enzyme $\alpha$-galactosidase (EC 3.2.1.22), an enzyme not found in the human digestive tract. Starch is a polysaccharide formed by a large number of glucose units. It is interesting to note that species of clade B, including Leuconostoc, Pediococcus, and Lactobacillus strains, were not able to metabolize starch. The species that can ferment starch included Lc. lactis ssp. lactis 1-3, 5, and 6 (clade A), and Lb. dextrinicus, Lb. gasseri, Lb. johnsonii, Lb. pasteurii, Lb. amylovorus, and Lb. gallinarum (clade C). The enzyme responsible for hydrolysis of starch molecules 


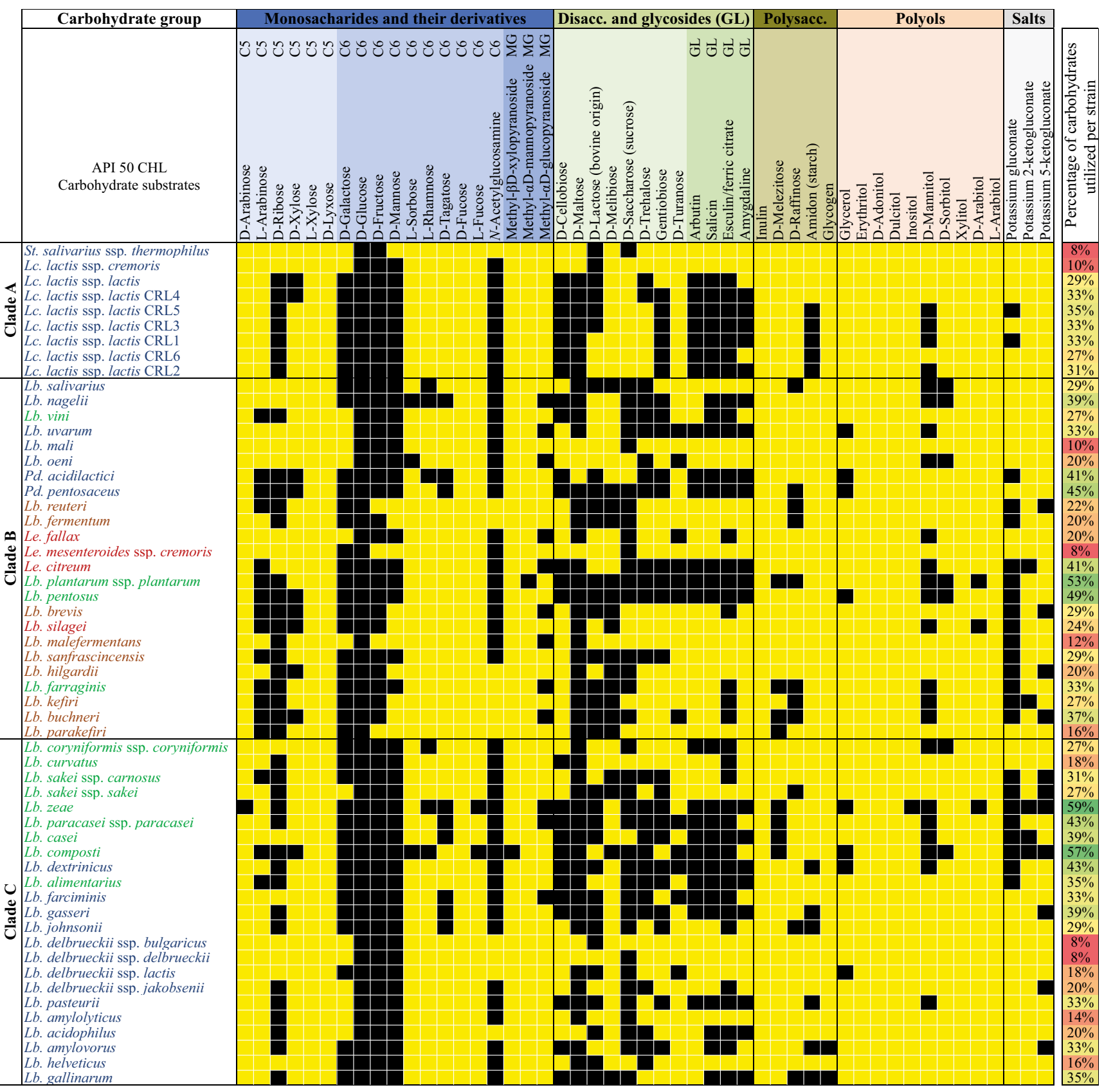

Percentage of carbohydrates utilized per studied group of strains

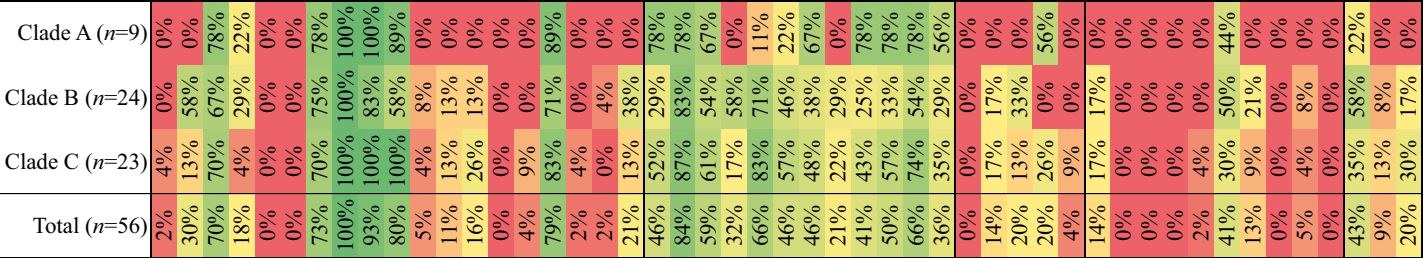

Fig. 4 Heatmap generated based on 49 carbohydrate fermentation profiles of 56 lactic acid bacteria (LAB) strains. All carbohydrate substrates (API $50 \mathrm{CHL}$ ) were categorized and grouped into monosaccharides and their derivatives, disaccharides and glycosides (GL), polysaccharides, polyols, and salts. LAB's capacity to metabolize the corresponding carbohydrate is represented as positive (black) or lack of fermentation (yellow). LAB were color-coded representing different fermentation patterns (type), according to Felis and Dellaglio (2007): homofermentative (blue), heterofermentative (red), facultatively heterofermentative (green), and obligately heterofermentative (brown). The LAB strains clustering (clades A-C) corresponds to the phylogenetic tree in Fig. 3. Numbers on the right represent the percentage of carbohydrates utilized per strain, while numbers on the bottom the percentage of carbohydrates utilized per studied group of strains. Gradient scale $0 \%$ (red)-100\% (green) 
yielding glucose and maltose is $\alpha$-amylase (E.C.3.2.1.1). Other two polysaccharides shown in Fig. 4 were inulin and glycogen. None of tested strains were able to utilize inulin, but $L b$. amylovorus and Lb. gallinarum were capable of fermenting glycogen.

A polyol is an alcohol containing three or more hydroxyl groups, and examples include glycerol, erythritol, D-adonitol, dulcitol, inositol, D-mannitol, D-sorbitol, xylitol, D-arabitol, and L-arabitol. The strains that were able to ferment glycerol belonged to $L b$. uvarum, $P d$. acidilactici, $P d$. pentosaceus, $L b$. pentosus, Lb. zeae, Lb. composti, Lb. dextrinicus, and $L b$. delbrueckii ssp. lactis. No strain in clade A was capable of degrading glycerol, commonly used as carbon source in biotechnology. Among all the polyols, D-mannitol is the sugar alcohol most widely fermented by LAB members of each clade, followed by D-sorbitol with the exception of members in clade A, which cannot degrade D-sorbitol. On the other hand, while three strains were capable of fermenting D-arabitol (Lb. plantarum ssp. plantarum, Lb. silagei, and Lb. zeae), only $L b$. zeae was able to degrade inositol. As for the remainder of the polyols, 56 analyzed LAB strains cannot ferment erythritol, D-adonitol, dulcitol, xylitol, and L-arabitol (Fig. 4).

The salts characterized included potassium gluconate, potassium 2-ketogluconate, and potassium 5-ketogluconate (Fig. 4). Potassium gluconate is the potassium salt of gluconic acid, which is obtained from glucose by fermentation and subsequent neutralization with a potassium source. Of the three salts characterized, potassium gluconate was the one most widely fermented by LAB members of each clade, followed by potassium 5-ketogluconate with the exception of members in clade A, which cannot metabolize this salt. Finally, five strains were capable of metabolizing potassium 2-ketogluconate being Le. citreum and Lb. kefiri (clade B), $L b$. zeae, Lb. casei, and Lb. composti (clade C) (Fig. 4).

\section{Association of phenotypic data to genomic data}

The genotype-phenotype association analysis was performed to identify significant associations between gene family expansions/contractions in the $56 \mathrm{LAB}$ strains in relation to their carbohydrate metabolism, based on three different correction methods for multiple testing, namely Bonferroni $(p<0.05)$, false discovery rate (FDR) $(p<0.01)$, and FDR $(p<0.05)$.

The results for Bonferroni correction, represented as a heatmap in Fig. 5, showed significant associations of 17 ortholog groups with 7 phenotypic traits related to carbohydrate metabolism. In Fig. 5, the 56 LAB strains clustered according to similarities in their carbohydrate metabolism, partially recovering the phylogenetic clades in Fig. 3. This implies that some of these metabolic traits evolved along the diversification of the $56 \mathrm{LAB}$ species. Three clusters were observed, but not clearly separated based on fermentation type. While the first cluster comprises from $L b$. sakei ssp. sakei to Lb. alimentarius, and excludes obligately heterofermentative species, the second cluster only includes homofermentative species, revealing similarities in their carbohydrate metabolism. By contrast, in the third cluster, the heterofermentative species grouped together, including facultatively and obligately, showing similar fermentation profiles. Among the strains of all the homofermentative species, we observed a general lack of genes belonging to multigene families associated with the phenotypes L-arabinose and D-melezitose. Similarly, the strains of obligately heterofermentative species were depleted of genes belonging to multigene families associated with the phenotypes D-mannose, arbutin, and salicin (Fig. 5).

The Lactococcus genus clustered together, as these strains basically showed the same carbohydrate profile, with a few exceptions. By contrast, species of the Pediococcus genus did not cluster according to their metabolic profiles. The main difference is that $P d$. acidilactici did not metabolize D-saccharose, in contrast to $P d$. pentosaceus. In addition, the orthogroup OG0000939, significantly associated with the metabolism of D-saccharose ( $p$ value $=6.19 \mathrm{e}-03$ ), was present only in $P d$. pentosaceus. Similarly, Leuconostoc species did not cluster together, since Le. citreum showed a slightly different metabolic profile compared to Le. fallax and Le. mesenteroides ssp. cremoris. In particular, Le. fallax and Le. mesenteroides ssp. cremoris have lost their ability to metabolize arbutin, salicin, D-cellobiose, D-mannose, and L-arabinose. The orthogroups significantly associated with these metabolisms were OG0000070, OG0000204, OG0000133, OG0000160, OG0000409, OG0001662, OG0001748, and OG0001480 (Fig. 5).

Differences between the three clusters defined by the heatmap lied down mainly in the ability of the strains to metabolize arbutin, salicin, and D-cellobiose (Fig. 5). Strains belonging to cluster 1 were often able to metabolize these three carbohydrates, in contrast to those belonging to clusters 2 and 3. Several orthogroups showed concomitant variations in the number of family members. For example, the number of genes in OG0000014 was at least 11 among strains that metabolize salicin and D-cellobiose, while merely 1 for the remaining. In fact, St. salivarius ssp. thermophilus, Lb. reuteri, Lb. sanfranciscensis, and $L b$. fermentum did not metabolize salicin and D-cellobiose, and have thus no genes belonging to OG0000014. Genes within this orthogroup were functionally annotated as RpiR family transcriptional regulator. Likewise, orthogroup OG0000070 was significantly associated with the metabolism of arbutin $(p$ value $=0.03)$ and salicin $(p$ value $=$ 0.01 ), and annotated as DeoR family transcriptional regulator. $L b$. zeae showed the largest number of genes in OG0000070, with eight members. Interestingly, all strains in clusters 2 and 3 lost their ability of fermenting arbutin and salicin; however, only heterofermentative species in cluster 3 have almost no genes belonging to this orthogroup. Another orthogroup 
Carbohydrates

Carbohydrates associated with OG

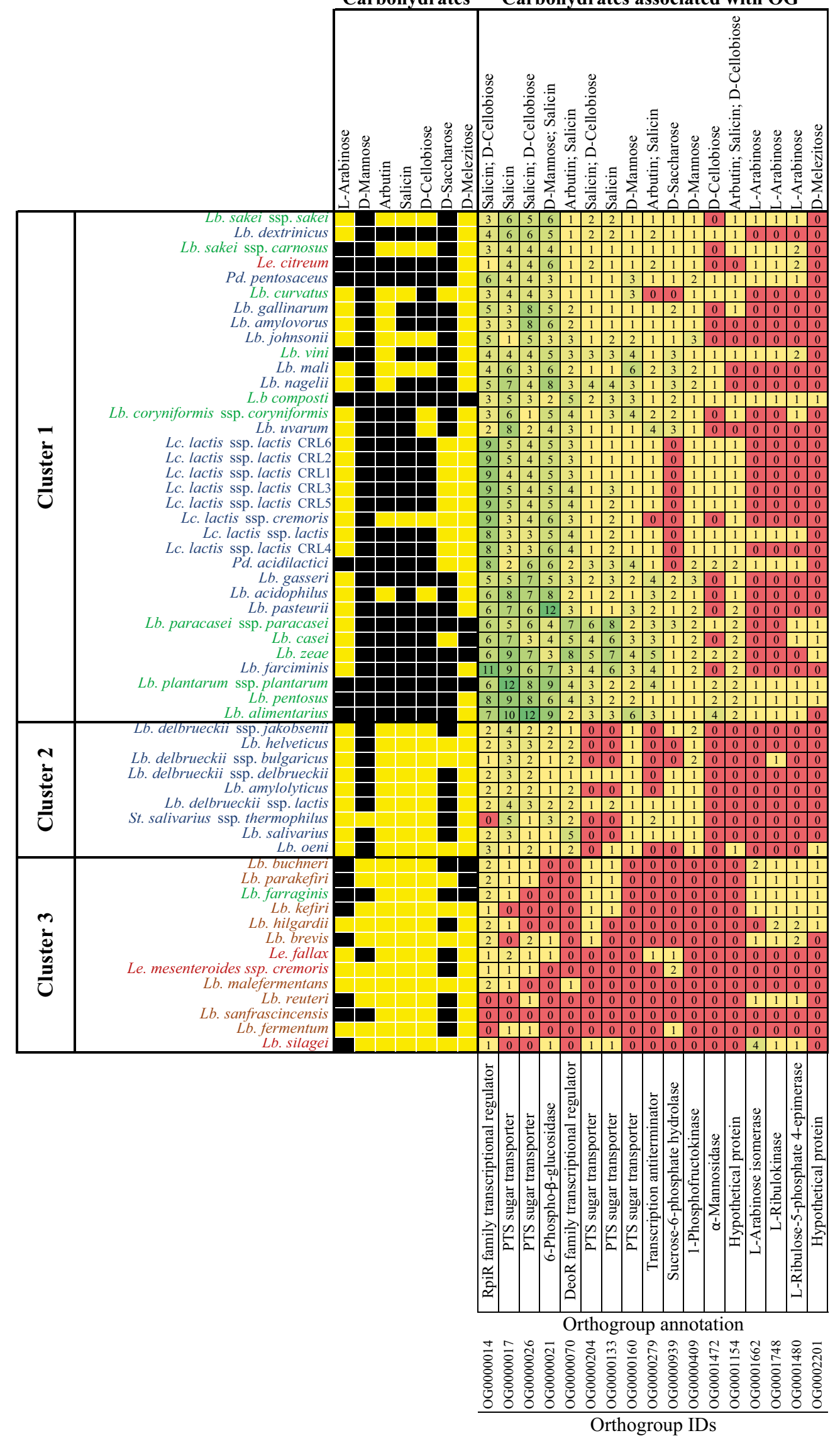


Fig. 5 Heatmap representing significant genotype-phenotype associations. The 17 orthogroups significantly associated with the metabolism of seven carbohydrates, as identified after Bonferroni correction $(p<0.05)$, is shown. LAB species were color-coded as homofermentative (blue), heterofermentative (red), facultatively heterofermentative (green), and obligately heterofermentative (brown). Phenotype information is represented in black/yellow color scheme, based on the LAB capacity to metabolize the corresponding carbohydrate: black (positive) and yellow (negative). Gene content of the $56 \mathrm{LAB}$ strains is represented in red/green color scheme, with green color indicating a greater number of genes for a given orthogroup

significantly associated with the metabolism of arbutin and salicin was OG0000279 ( $p$ values $=0.02$ and $7.35 \mathrm{e}-04$, respectively), which has been annotated as transcription antiterminator. Unlike in cluster 2 and 3, all strains comprising cluster one had at least one gene in OG0000279, except $L b$. curvatus and Lc. lactis ssp. cremoris, where this multigene family was absent (Fig. 5).

Orthogroups OG0000017, OG0000026, OG0000204, OG0000133, and OG0000160 were also associated with the metabolism of salicin, D-cellobiose, and D-mannose. These five orthogroups contained at least one gene present in all the LAB of cluster 1, with OG0000017 and OG0000026 harboring the greatest number of genes. In fact, $L b$. plantarum ssp. plantarum and Lb. alimentarius contained 12 members in orthogroups OG0000017 and OG0000026, respectively. Regarding cluster 2 , these orthogroups were mostly present in homofermentative species, in comparison to heterofermentative strains in cluster 3 , where these families were nearly absent, or even absent for orthogroup OG0000160. While the orthogroup OG0000160 was specifically associated with the D-mannose metabolism, OG0000017 and OG0000026 were associated with salicin, and salicin and D-cellobiose, respectively. Genes belonging to all these orthogroups were functionally annotated as phosphotransferase (PTS) sugar transporters (Fig. 5). The capacity of utilizing salicin, D-cellobiose and D-mannose indicates that the genome of these LAB encode for proteins acting as specific transporters, such as PTS-salicin, PTS-cellobiose, and PTS-mannose.

The multigene family annotated as 6-phospho- $\beta$-glucosidase (OG0000021) was significantly associated with the ability to utilize D-mannose and salicin, as sucrose-6-phosphate hydrolase (OG0000939) was with D-saccharose, 1-phosphofructokinase (OG0000409) with D-mannose, and $\alpha$-mannosidase (OG0001472) with D-cellobiose (Fig. 5). All LAB in cluster 1 and 2 have different copies of the 6-phospho- $\beta$-glucosidase and 1-phosphofructokinase genes. By contrast, heterofermentative LAB strains in cluster 3 have lost their 6-phospho- $\beta$ glucosidase and 1-phosphofructokinase genes, excepting $L b$. brevis, Le. fallax, and Lb. silagei, which retain one gene of the 6 -phospho- $\beta$-glucosidase. In cluster 1 , the sucrose-6-phosphate hydrolase multigene family was only absent in Lb. curvatus, Lc. lactis group, and $P d$. acidilactici strains, whereas in cluster 2 and
3, different homofermentative and heterofermentative LAB species lost their ability to ferment D-saccharose, as well as their associated genes (OG0000939). All homofermentative and heterofermentative strains in clusters 2 and 3 lost the ability to ferment D-cellobiose, as well as the $\alpha$-mannosidase genes (OG0001472), which are not found in any member of these clusters (Fig. 5).

Other statistically significant genotype-phenotype association were identified between L-arabinose and the following multigene families OG0001662, OG0001748, and OG0001480, which were annotated as L-arabinose isomerase $($ EC 5.3.1.4; $p$ value $=1.41 \mathrm{e}-05)$, L-ribulokinase $($ EC 2.7.1.16; $p$ value $=5.42 \mathrm{e}-04)$, and L-ribulose-5-phosphate 4-epimerase (EC 5.1.3.4, $p$ value $4.63 \mathrm{e}-03$ ). As for the multigene family Larabinose isomerase (OG0001662), Lb. silagei that metabolize L-arabinose contained four gene copies, Lb. buchneri contained two, and the rest contained one gene each. In general, correlation between the presence of L-arabinose isomerase, L-ribulokinase, and L-ribulose-5-phosphate 4-epimerase genes and the fermentation type was identified, whereby heterofermentative strains showed a greater number of these genes than the homofermentative ones. Importantly, species metabolizing and non-metabolizing L-arabinose are interspersed among Lactobacillus and Lactococcus, as well as Leuconostoc genus. This confirms that this genotypephenotype association is not spuriously reflecting the underlying phylogenetic relationship, and reveals that multiple species underwent independent changes in the arabinose metabolism. Remarkably, and in contrast to the majority of carbohydrates, the isomer L-arabinose is more common than D-arabinose in nature. Collectively, this suggests that only those LAB strains able to transform L- into D-arabinose, due to the expansion of these three multigene families, are also able to subsequently metabolize D-arabinose.

Moreover, the genotype-phenotype association analysis revealed that two orthogroups predicted as unknown hypothetical proteins (functionally unannotated families; OG0001154 and OG0002201) were involved in a series of carbohydrate metabolic functions (Fig. 5). The orthogroup OG0001154 was significantly associated with the utilization of arbutin, salicin, and D-cellobiose. In cluster 1, only a few strains lost the genes of this orthogroup, whereas it was absent among homofermentative and heterofermentative species of clusters 2 and 3, with the exception of $L b$. oeni, which contained one gene only. The other orthogroup of unidentified function was OG0002201, and it was significantly associated with Dmelezitose metabolism. With the exception of $L b$. oeni (homofermentative), only heterofermentative strains contained OG0002201 genes.

The results above proved that this method can be used to identify in which metabolic pathways the unannotated multigene families were involved, and consequently to gain deeper insights into their function. 


\section{Discussion}

LABs are used worldwide industrially in the manufacture of fermented foods and beverages (Holzapfel and Wood 2014), because their metabolic products improve nutritional value, organoleptic properties, as well as the microbiological safety of food products (Thierry et al. 2015). Since LAB use preferably carbohydrates as the primary carbon and energy sources, understanding the genetic basis of their utilization in metabolic pathways is essential to optimize the fermentative processes.

In this study, the comparison of LAB genomes revealed 219 single-copy genes shared among the 56 strains, which is known as the core genome. In another study comparing 20 Lactobacillus genomes, the core gene set was estimated to include 383 genes (Kant et al. 2011). Increasing the number of genomes to 213 reduced the core gene set to 73 genes (Sun et al. 2015). The core gene set is not only reduced with the number of compared genomes but also with the phylogenetic distances between them and the incompleteness of genome assemblies. For instance, Lukjancenko and colleagues (Lukjancenko et al. 2012) compared $81 \mathrm{LAB}$ genomes from 6 different genera, and found that the core genome contains 63 genes. A greater core gene set of 172 single-copy genes was estimated in another study including 174 type strains from only 2 genera, Lactobacillus and Pediococcus (Zheng et al. 2015). In this study, the core gene set of 219 orthologous groups was slightly greater than those estimated in previous studies, probably reflecting that all genomes investigated were assembled at least at the scaffold level, precisely to improve gene completeness.

Functional annotation revealed that these 219 genes are mostly involved in nitrogen metabolism (data not shown). This suggests that these core genes are essential. Singlecopy genes were unlikely duplicated or lost during evolution, implying they are true orthologs. Therefore, they reflect the divergence and phylogenetic relationship between the $\mathrm{LAB}$ species. Leveraging these 219 core genes, the phylogenetic tree was constructed, rooted assuming St. salivarius ssp. thermophilus and Lc. lactis as outgroup species (Fig. 3). Early after the first genomic studies, Lactobacillus species were found to belong to two separate clades (Makarova et al. 2006; Makarova and Koonin 2007; O'Sullivan et al. 2009; Salvetti et al. 2018). Our maximum-likelihood (ML) phylogenetic reconstruction recovered these two major Lactobacillus clades, referred as clade B and C, with high bootstrap support (Fig. 3). Nevertheless, the species that comprised these two clades have been traditionally controversial. The maximum phylogenetic uncertainty is associated with the species of the $L b$. casei group, which harbor a large diversity in gene content across strains, including horizontal gene transfer (HGT) from Lactobacilli species of clade B (Broadbent et al. 2012). Indeed, multiple studies placed $L b$. casei species within clade C (Makarova et al. 2006; Makarova and Koonin 2007; Claesson et al. 2008; Zhang et al. 2011; Salvetti et al. 2013; Sun et al. 2015), whereas a few others within clade B (Liu et al. 2008; O'Sullivan et al. 2009; Lukjancenko et al. 2012; Zheng et al. 2015). Our reconstruction based on a greater number of core genes supports the former hypothesis, embedding the $L b$. casei group within group C (Fig. 3). Our phylogenomic tree also support Leuconostoc and Pediococcus as emerging within the Lactobacillus species of clade B, confirming previous results (Makarova et al. 2006; Makarova and Koonin 2007; Claesson et al. 2008; Liu et al. 2008; Zhang et al. 2011; Salvetti et al. 2013; Sun et al. 2015).

Mapping the fermentative types of $56 \mathrm{LAB}$ revealed that some phylogenetically related species have different fermentation capabilities, a phenomenon that occurred within both, clades $\mathrm{B}$ and $\mathrm{C}$, and that has been previously reported (Hammes and Vogel 1995; Felis and Dellaglio 2007; Pot et al. 2014), but disregarded by Zheng and colleagues (Zheng et al. 2015) in a more recent study. This incongruence could be explained by misclassifying the fermentation capabilities of a very few Lactobacillus strains. For example, $L b$. vini has been assigned as a homofermentative species (Zheng et al. 2015), despite it produces small amounts of ethanol from arabinose and ribose (Felis and Dellaglio 2007; Endo and Dicks 2014), which were indeed degraded by Lb. vini in this study (Fig. 4).

A similar approach has been recently adopted to map lifestyle transitions (from free-living to host-adapted) onto certain phylogenetic nodes (Duar et al. 2017). Interestingly, the phylogenetic clades in this study mirror the grouping of these lifestyles. More specifically, most obligately heterofermentative strains of phylogenetic clade B, such as Lb. brevis and $L b$. parakefiri, were classified as free-living (Duar et al. 2017). In contrast, all homofermentative strains of clade $\mathrm{C}$, and for which lifestyle information is available, were classified as adapted to vertebrates (Fig. 3). Taken together, this suggests that fermentation types and lifestyles strongly shaped LAB genomic evolution. For example, and with the most notable exception of the $L b$. delbrueckii group, GC content tends to be lower in homofermentative species (Fig. 3), most of which are hostadapted bacteria (Duar et al. 2017). Drastic variation in GC content is usually associated with gene acquisition through HGT (Garcia-Vallvé et al. 2000; Guindon and Perrière 2001), suggesting that heterofermentative capabilities could have been acquired from phylogenetically distant species. Regardless of the mechanism of gene acquisition, the gene repertoire of Lactobacilalles species is known to be highly dynamic (Zheng et al. 2015; Papizadeh et al. 2017), as reflected by the limited number of core genes found in this and other studies (O'Sullivan et al. 2009; Kant et al. 2011; Lukjancenko et al. 2012). Therefore, most of the LAB phenotypic variation is expected to result from gene gain and loss processes. In Lactobacillus, some genes related to carbohydrate utilization, for example, have 
been inferred to be acquired by HGT (Barrangou et al. 2003; Klaenhammer et al. 2005). Likewise, Zheng and colleagues (Zheng et al. 2015) found that genes lost in heterofermentative species are mostly associated with carbohydrate metabolism. Collectively, this supports gene variation as a major source of functional innovation in carbohydrate metabolism, and justifies genotype-phenotype association studies at the orthogroup level. Phenotyping different features of the carbohydrate metabolism revealed that $\mathrm{LAB}$ are separated in three metabolic clusters (Fig. 4). These clusters do not fully recapitulate the exact phylogenetic clades. This implies that some of these metabolic traits evolved along the diversification of the $56 \mathrm{LAB}$ species, but others might have been acquired through HGT or independently lost in multiple lineages. Interestingly, the presence of certain genes not always implies degradation of the associated carbohydrate. For example, St. thermophilus was not able to metabolize salicin despite harboring multiple genes that in the other species were associated with salicin degradation (e.g., OG0000017, in Figs. 4 and 5). This is in line with St. thermophilus undergoing a massive pseudogenization process (gene inactivation), which is also observed in Lb. helveticus and Lb. delbrueckii (Bolotin et al. 2004; O’Sullivan et al. 2009). Conversely, Lb. sanfranciscensis was able to utilize diverse sources of carbohydrates, such as Dmannose (Fig. 4), albeit it lacked all gene families found to be significantly associated with its degradation (Fig. 5). These findings emphasize that phenotypes cannot be always inferred from the presence/absence of specific genes, but require explicitly integrating phenotypic information. Yet, this study revealed another interesting pattern. Metabolic cluster 3 contained all obligately heterofermentative strains (Fig. 5), and the association results indicated that all members within this cluster lacked 1phospofructokinase (PFK), in contrast to the other two metabolic clusters, where this gene was present at least as single-copy (Fig. 5). PFK was found to be a key gene distinguishing hetero- and homofermentative species in previous studies (Morita et al. 2008; Zheng et al. 2015), and more recently confirmed based on phylogenetic framework (Salvetti et al. 2018). The association study implemented in this work provides further insights, revealing that PFK is indispensable not only for mediating fructose-6-P phosphorylation but also for D-mannose degradation during homofermentation. Since PFK acts on the homofermentative pathway, species lacking this enzyme produce $\mathrm{CO}_{2}$, ethanol, and lactate, through the heterofermentative pathway. Besides the PFK absence, obligately but also facultative heterofermentative species are partially characterized by the presence of three genes, represented by OG0001662, OG0001748, and OG0001480 (Fig. 5). These genes are associated with the degradation of L-arabinose, and annotated as Larabinose isomerase, L-ribulose kinase, and ribulose phosphate epimerase, respectively. BLAST homology searches suggested that these genes correspond to $\operatorname{araA}$, $\operatorname{araB}$, and $\operatorname{araD}$, conforming the $a r a B A D$ operon. In Escherichia coli, this operon has been described to degrade L-arabinose into xylulose-5P, an essential compound in the heterofermentative pathway (Schleif 2010). Therefore, obligately heterofermentative strains are characterized by the absence of 1-phospofructokinase, and to a lesser extent by the presence of the three enzymes forming the $a r a B A D$ operon (Fig. 5).

Metabolic clusters 1 and 2 excluded obligately heterofermentative strains, and only contained homofermentative and facultative heterofermentative LAB (Fig. 5). Particularly, cluster 1 showed an increased number of genes annotated as (i) carbohydrate phosphotransferase system (PTS); (ii) transcriptional regulators, such as the RpiR and DeoR families, and a transcription antiterminator; and (iii) glycosyl hydrolases, namely 6-phospho- $\beta$-glucosidase and sucrose-6phosphate hydrolase. Interestingly, all these genes participate in the uptake of different carbohydrates, and their subsequent hydrolysis. PTS proteins are known to first import and phosphorylate carbohydrate substrates, such as salicin, D-cellobiose, and D-mannose. According to the results of this study, their degradation is significantly associated with the number of PTS transporters (Fig. 5). This is in line with other studies that have also described variation in PTS abundance across species, depending on their fermentation capabilities. More specifically, PTS components have been found to be numerous in homofermentative strains, while rarely in heterofermentative strains (Reizer et al. 1988; Bolotin et al. 2001; Michlmayr and Kneifel 2014). Despite being rare, PTS components had been described in only two obligately heterofermentative species, namely Lb. brevis (Saier et al. 1996) and Lb. fermentum (Zhang et al. 2013). This study corroborates PTS presence in $L b$. brevis and Lb. fermentum, but also expands this observation to the type strains of the following obligately heterofermentative species: $L b$. buchneri, Lb. parakefiri, Lb. kefiri, Lb. hilgardii, Lb. malefermentans, and Lb. reuteri (Fig. 5).

Following carbohydrate uptake by PTS proteins, transcriptional regulators modulate the degradation of $\beta$-glucosides like D-cellobiose, as well as aromatic $\beta$-glucosides, such as salicin and arbutin (Bardowski et al. 1994; Sonowal et al. 2013). All three carbohydrates, D-cellobiose, salicin, and arbutin, were shown in this study to be significantly associated with transcriptional regulators, supporting their role in the degradation of these $\beta$-glucosides (Fig. 5). Finally, glycosyl hydrolases are known to be also involved in the breakdown of $\beta$-glucosides in the cytoplasm. This association was also reflected in our results, as two glycosyl hydrolases were associated with the metabolism of D-mannose, salicin, and D-saccharose (Fig. 5). Interestingly, obligately heterofermentative strains within metabolic cluster 3 are often devoid of these two glycosyl hydrolases (Fig. 5), in line with previous studies finding a lower amount of glycosyl hydrolases in obligately heterofermentative Lactobacillus species (Michlmayr et al. 2013). More interestingly, PTSs, transcriptional regulators, and glycosyl hydrolases are often arranged in gene clusters, 
suggesting they orchestrate the co-regulation of carbohydrate metabolism (Morita et al. 2009), as potentially reflected by the results of the present study found for cluster 1 (Fig. 5).

In conclusion, genotype-phenotype association enabled the identification of genes involved and responsible for the transport and metabolization of specific carbon sources. Functional annotation of those orthogroups shed light into the metabolic pathways underlying different fermentative capabilities of selected LAB strains. As an example, PFK absence in obligately heterofermentative strains mirrored its essential function in the homolactic fermentation pathway. Complementarily, the results of this study also revealed novel associations between unannotated orthogroups (i.e., hypothetical proteins) with essential traits of the LAB carbohydrate metabolism, including OG0002201 (involved in D-melezitose degradation) and OG0001154 (with arbutin, salicin, and D-cellobiose). This highlights how genotype-phenotype associations can provide deeper insights into the function of hypothetical proteins. Further validation is required to confirm these findings, as well as to elucidate the potential roles of these genes in carbohydrate metabolism, which is of paramount importance for industrial applications.

Acknowledgements We thank Dr. Kasper Nielsen (Carlsberg Research Laboratory, Copenhagen, Denmark) for his helpful comments on the manuscript.

Author contribution statements G.B.M and M. M designed the project. G.B.M and I. D performed the phenotypic characterization. A. C and G.B.M performed the computational analyses. G.B.M and M. M wrote the paper with input from all authors. M.M. and J. F supervised the project.

Funding This study was supported by Carlsberg Foundation (CF140450) under the Project "Tapping the biodiversity of Lactobacilli for novel fermented beverages."

\section{Compliance with ethical standards}

Conflict of interest The authors declare that they have no conflict of interest.

Ethical approval This article does not contain any studies with human participants or animals performed by any of the authors.

Open Access This article is distributed under the terms of the Creative Commons Attribution 4.0 International License (http:// creativecommons.org/licenses/by/4.0/), which permits unrestricted use, distribution, and reproduction in any medium, provided you give appropriate credit to the original author(s) and the source, provide a link to the Creative Commons license, and indicate if changes were made.

Publisher's note Springer Nature remains neutral with regard to jurisdictional claims in published maps and institutional affiliations.

\section{References}

Altschul SF, Gish W, Pennsylvania T, Park U (1990) Basic local alignment search tool. J Mol Biol 215:403-410. https://doi.org/10.1016/ S0022-2836(05)80360-2

Bardowski J, Ehrlich SD, Chopin A (1994) BglR protein, which belongs to the $\mathrm{BglG}$ family of transcriptional antiterminators, is involved in $\beta$-glucoside utilization in Lactococcus lactis. J Bacteriol 176(18): $5681-5685$

Barrangou R, Altermann E, Hutkins R, Cano R, Klaenhammer TR (2003) Functional and comparative genomic analyses of an operon involved in fructooligosaccharide utilization by Lactobacillus acidophilus. Proc Natl Acad Sci 100(15):8957-8962. https://doi. org/10.1073/pnas. 1332765100

Bayjanov JR, Starrenburg MJC, van der Sijde MR, Siezen RJ, van Hijum SAFT (2013) Genotype-phenotype matching analysis of 38 Lactococcus lactis strains using random forest methods. BMC Microbiol 13:68. https://doi.org/10.1186/1471-2180-13-68

Benjamini Y, Hochberg Y (1995) Controlling the false discovery rate: a practical and powerful approach to multiple testing. J R Stat Soc 57(1):289-300

Bland JM, Altman DG (1995) Multiple significance tests: the Bonferroni method. BMJ 310(6973):170. https://doi.org/10.1136/bmj.310. 6973.170

Bolotin A, Quinquis B, Renault P, Sorokin A, Ehrlich SD, Kulakauskas S, Lapidus A, Goltsman E, Mazur M, Pusch GD, Fonstein M, Overbeek R, Kyprides N, Purnelle B, Prozzi D, Ngui K, Masuy D, Hancy F, Burteau S, Boutry M, Delcour J, Goffeau A, Hols P (2004) Complete sequence and comparative genome analysis of the dairy bacterium Streptococcus thermophilus. Nat Biotechnol 22(12): 1554-1558. https://doi.org/10.1038/nbt1034

Bolotin A, Wincker P, Mauger S, Jaillon O, Malarme K, Weissenbach J, Ehrlich SD, Sorokin A (2001) The complete genome sequence of the lactic acid bacterium Lactococcus lactis ssp lactis IL1403. Genome Res 11:731-753. https://doi.org/10.1101/gr.169701

Bosma EF, Forster J, Nielsen AT (2017) Lactobacilli and pediococci as versatile cell factories - evaluation of strain properties and genetic tools. Biotechnol Adv 35(4):419-442. https://doi.org/10.1016/j. biotechadv.2017.04.002

Brbić M, Piškorec M, Vidulin V, Kriško A, Šmuc T, Supek F (2016) The landscape of microbial phenotypic traits and associated genes. Nucleic Acids Res 44(21):10074-10090. https://doi.org/10.1093/ nar/gkw964

Broadbent JR, Neeno-Eckwall EC, Stahl B, Tandee K, Cai H, Morovic W, Horvath P, Heidenreich J, Perna NT, Barrangou R, Steele JL (2012) Analysis of the Lactobacillus casei supragenome and its influence in species evolution and lifestyle adaptation. BMC Genomics 13:533. https://doi.org/10.1186/1471-2164-13-533

Ceapa C, Lambert J, van Limpt K, Wels M, Smokvina T, Knol J, Kleerebezem M (2015) Correlation of Lactobacillus rhamnosus genotypes and carbohydrate utilization signatures determined by phenotype profiling. Appl Environ Microbiol 81(16):5458-5470. https://doi.org/10.1128/AEM.00851-15

Chai J, Kora G, Ahn TH, Hyatt D, Pan C (2014) Functional phylogenomics analysis of bacteria and archaea using consistent genome annotation with UniFam. BMC Evol Biol 14(1):1-13. https://doi.org/10.1186/s12862-014-0207-y

Chen PE, Shapiro BJ (2015) The advent of genome-wide association studies for bacteria. Curr Opin Microbiol 25:17-24. https://doi.org/ 10.1016/j.mib.2015.03.002

Claesson MJ, van Sinderen D, O'Toole PW (2008) Lactobacillus phylogenomics - towards a reclassification of the genus. Int J Syst Evol Microbiol 58(12):2945-2954. https://doi.org/10.1099/ijs.0. 65848-0 
Deurenberg RH, Bathoorn E, Chlebowicz MA, Couto N, Ferdous M, García-Cobos S, Kooistra-Smid AMD, Raangs EC, Rosema S, Veloo ACM, Zhou K, Friedrich AW, Rossen JWA (2017) Application of next generation sequencing in clinical microbiology and infection prevention. J Biotechnol 243:16-24. https://doi.org/ 10.1016/j.jbiotec.2016.12.022

Duar RM, Lin XB, Zheng J, Martino ME, Grenier T, Pérez-Muñoz ME, Leulier F, Gänzle M, Walter J (2017) Lifestyles in transition: evolution and natural history of the genus Lactobacillus. FEMS Microbiol Rev 41:S27-S48. https://doi.org/10.1093/femsre/fux030

Dutilh BE, Backus L, Edwards RA, Wels M, Bayjanov JR, Sacha AF (2013) Explaining microbial phenotypes on a genomic scale: GWAS for microbes. Brief Funct Genomics 12(4):366-380. https://doi.org/10.1093/bfgp/elt008

Emms DM, Kelly S (2015) OrthoFinder: solving fundamental biases in whole genome comparisons dramatically improves orthogroup inference accuracy. Genome Biol 16(1):1-14. https://doi.org/10.1186/ s13059-015-0721-2

Endo A, Dicks LMT (2014) Physiology of the LAB. In: Holzapfel WH, Wood BJB (eds) Lactic acid bacteria: biodiversity and taxonomy. John Wiley \& Sons, Hoboken, NJ, pp 13-20

Facklam R (2002) What happened to the Streptococci: overview of taxonomic and nomenclature changes. Clin Microbiol Rev 15(4):613630. https://doi.org/10.1128/CMR.15.4.613-630.2002

Felis GE, Dellaglio F (2007) Taxonomy of lactobacilli and bifidobacteria. Curr Issues Intest Microbiol 8:44-61

Freddolino PL, Goodarzi H, Tavazoiea S (2014) Revealing the genetic basis of natural bacterial phenotypic divergence. J Bacteriol 196(4): 825-839. https://doi.org/10.1128/JB.01039-13

Garcia-Vallvé S, Romeu A, Palau J (2000) Horizontal gene transfer in bacterial and archaeal complete genomes. Genome Res 10:1719 1725. https://doi.org/10.1101/gr.130000

Guindon S, Perrière G (2001) Intragenomic base content variation is a potential source of biases when searching for horizontally transferred genes. Mol Biol Evol 18(9):1838-1840

Gurevich A, Saveliev V, Vyahhi N, Tesler G (2013) QUAST: quality assessment tool for genome assemblies. Bioinformatics 29(8): 1072-1075. https://doi.org/10.1093/bioinformatics/btt086

Hadley W, Hester J, Chang W (2017) Tools to make developing R packages easier: devtools. R package version 1.13.3. https://CRAN.Rproject.org/package $=$ devtools

Hammes WP, Hertel C (2009) Genus I. Lactobacillus Beijerinck 1901, $212^{\mathrm{AL}}$. In: de Vos P, Garrity G, Jones D, Krieg N, Ludwig W, Rainey F, Schleifer K, Whitman W (eds) Bergey's manual of systematic bacteriology, vol 3, 2nd edn. The firmicutes. Springer, Heidelberg, pp 465-511

Hammes WP, Vogel RF (1995) The genus Lactobacillus. In: Wood BJB, Holzapfel WH (eds) The genera of lactic acid bacteria. Blackie Academic \& Professional, London, pp 19-54

Holzapfel WH, Wood BJB (2014) Lactic acid bacteria: biodiversity and taxonomy. John Wiley \& Sons, Hoboken, NJ

Hu Z, Bao J, Reecy JM (2008) CateGOrizer: a web-based program to batch analyze gene ontology classification categories. Online $\mathrm{J}$ Bioinforma 9(2):108-112

Hyatt D, Chen GL, LoCascio PF, Land ML, Larimer FW, Hauser LJ (2010) Prodigal: prokaryotic gene recognition and translation initiation site identification. BMC Bioinformatics 11:119. https://doi. org/10.1186/1471-2105-11-119

Kant R, Blom J, Palva A, Siezen RJ, de Vos WM (2011) Comparative genomics of Lactobacillus. Microb Biotechnol 4(3):323-332. https://doi.org/10.1111/j.1751-7915.2010.00215.x

Katoh K, Standley DM (2013) MAFFT multiple sequence alignment software version 7: improvements in performance and usability. Mol Biol Evol 30:772-780. https://doi.org/10.1093/molbev/mst010

Klaenhammer TR, Barrangou R, Buck BL, Azcarate-Peril MA, Altermann E (2005) Genomic features of lactic acid bacteria effecting bioprocessing and health. FEMS Microbiol Rev 29:393409. https://doi.org/10.1016/j.femsre.2005.04.007

Klemm E, Dougan G (2016) Advances in understanding bacterial pathogenesis gained from whole-genome sequencing and phylogenetics. Cell Host Microbe 19(5):599-610. https://doi.org/10.1016/j.chom. 2016.04.015

Liu M, Nauta A, Francke C, Siezen RJ (2008) Comparative genomics of enzymes in flavor-forming pathways from amino acids in lactic acid bacteria. Appl Environ Microbiol 74(15):4590-4600. https://doi. org/10.1128/AEM.00150-08

Lukjancenko O, Ussery DW, Wassenaar TM (2012) Comparative genomics of Bifidobacterium, Lactobacillus and related probiotic genera. Microb Ecol 63:651-673. https://doi.org/10.1007/s00248-0119948-y

Makarova KS, Koonin EV (2007) Evolutionary genomics of lactic acid bacteria. J Bacteriol 189(4):1199-1208. https://doi.org/10.1128/JB. 01351-06

Makarova KS, Slesarev A, Wolf Y, Sorokin A, Mirkin B, Koonin EV, Pavlov A, Pavlova N, Karamychev V, Polouchine N, Shakhova V, Grigoriev I, Lou Y, Rohksar D, Lucas S, Huang K, Goodstein DM, Hawkins T, Plengvidhya V, Welker DL, Hughes JE, Goh Y, Benson A, Baldwin KA, Lee J-H, Díaz-Muñiz I, Dosti B, Smeianov VV, Wechter W, Barabote R, Lorca GL, Altermann E, Barrangou R, Ganesan B, Xie Y, Rawsthorne H, Tamir D, Parker C, Breidt F, Broadbent JR, Hutkins R, O’Sullivan D, Steele JL, Unlu G, Saier MH, Klaenhammer TR, Richardson P, Kozyavkin S, Weimer BC, Mills DA (2006) Comparative genomics of the lactic acid bacteria. Proc Natl Acad Sci U S A 103(42):15611-15616. https://doi.org/10. 1073/pnas.0607117103

Michlmayr H, Hell J, Lorenz C, Böhmdorfer S, Rosenau T, Kneifel W (2013) Arabinoxylan oligosaccharide hydrolysis by family 43 and 51 glycosidases from Lactobacillus brevis DSM 20054. Appl Environ Microbiol 79(21):6747-6754. https://doi.org/10.1128/ AEM.02130-13

Michlmayr H, Kneifel W (2014) $\beta$-Glucosidase activities of lactic acid bacteria: mechanisms, impact on fermented food and human health. FEMS Microbiol Lett 352(1):1-10. https://doi.org/10.1111/15746968.12348

Morita H, Toh H, Fukuda S (2008) Comparative genome analysis of Lactobacillus reuteri and Lactobacillus fermentum reveal a genomic island for reuterin and cobalamin producion. DNA Res 15(3):151161. https://doi.org/10.1093/dnares/dsn009

Morita H, Toh H, Oshima K, Murakami M, Taylor TD, Igimi S, Hattori M (2009) Complete genome sequence of the probiotic Lactobacillus rhamnosus ATCC 53103. J Bacteriol 191(24):7630-7631. https:// doi.org/10.1128/JB.01287-09

Neuwirth E (2014) RColorBrewer: ColorBrewer palettes. R package version 1.1-2. https://CRAN.R-project.org/package=RColorBrewer

O’Sullivan O, O'Callaghan J, Sangrador-Vegas A, McAuliffe O, Slattery L, Kaleta P, Callanan M, Fitzgerald GF, Ross RP, Beresford T (2009) Comparative genomics of lactic acid bacteria reveals a niche-specific gene set. BMC Microbiol 9(1):50. https://doi.org/10. 1186/1471-2180-9-50

Papizadeh M, Rohani M, Nahrevanian H, Javadi A, Pourshafie MR (2017) Probiotic characters of Bifidobacterium and Lactobacillus are a result of the ongoing gene acquisition and genome minimization evolutionary trends. Microb Pathog 111:118-131. https://doi. org/10.1016/j.micpath.2017.08.021

Pessione E (2012) Lactic acid bacteria contribution to gut microbiota complexity: lights and shadows. Front Cell Infect Microbiol 2:115. https://doi.org/10.3389/fcimb.2012.00086

Pot B, Felis G, De Bruyne K, Tsakalidou E, Papadimitriou K, Leisner J, Vandamme P (2014) The genus Lactobacillus. In: Holzapfel WH, Wood BJB (eds) Lactic acid bacteria: biodiversity and taxonomy. John Wiley \& Sons, Hoboken, NJ, pp 249-353 
Pretzer G, Snel J, Molenaar D, Wiersma A, Bron PA, Lambert J, de Vos WM, van der Meer R, Smits MA, Kleerebezem M (2005) Biodiversity-based identification and functional characterization of the mannose-specific adhesin of Lactobacillus plantarum. J Bacteriol 187(17):6128-6136. https://doi.org/10.1128/JB.187.17. 6128

Reizer J, Peterkofsky A, Romano AH (1988) Evidence for the presence of heat-stable protein (HPr) and ATP-dependent HPr kinase in heterofermentative lactobacilli lacking phosphoenolpyruvate: glycose phosphotransferase activity. Proc Natl Acad Sci U S A 85(7):2041-2045. https://doi.org/10.1073/pnas.85.7.2041

Ruppé E, Cherkaoui A, Lazarevic V, Emonet S, Schrenzel J (2017) Establishing genotype-to-phenotype relationships in bacteria causing hospital-acquired pneumonia: a prelude to the application of clinical metagenomics. Antibiotics 6(4):30. https://doi.org/10. 3390/antibiotics6040030

Saier MH, Ye JJ, Klinke S, Nino E (1996) Identification of an anaerobically induced phosphoenolpyruvate-dependent fructose-specific phosphotransferase system and evidence for the EmbdenMeyerhof glycolytic pathway in the heterofermentative bacterium Lactobacillus brevis. J Bacteriol 178(1):314-316. https://doi.org/10. 1128/jb.178.1.314-316.1996

Salvetti E, Fondi M, Fani R, Torriani S, Felis GE (2013) Evolution of lactic acid bacteria in the order Lactobacillales as depicted by analysis of glycolysis and pentose phosphate pathways. Syst Appl Microbiol 36(5):291-305. https://doi.org/10.1016/j.syapm.2013. 03.009

Salvetti E, Harris HMB, Felis GE, O'Toole PW (2018) Comparative genomics reveals robust phylogroups in the genus Lactobacillus as the basis for reclassification. Appl Environ Microbiol 84. https://doi. org/10.1128/AEM.00993-18

Schleif R (2010) AraC protein, regulation of the L-arabinose operon in Escherichia coli, and the light switch mechanism of AraC action. FEMS Microbiol Rev 34(5):779-796. https://doi.org/10.1111/j. 1574-6976.2010.00226.x

Siezen RJ, Bayjanov JR, Felis GE, van der Sijde MR, Starrenburg M, Molenaar D, Wels M, van Hijum SAFT, van Hylckama Vlieg JET (2011) Genome-scale diversity and niche adaptation analysis of Lactococcus lactis by comparative genome hybridization using multi-strain arrays. Microb Biotechnol 4(3):383-402. https://doi. org/10.1111/j.1751-7915.2011.00247.x

Siezen RJ, Tzeneva VA, Castioni A, Wels M, Phan HTK, Rademaker JLW, Starrenburg MJC, Kleerebezem M, van Hylckama Vlieg JET (2010) Phenotypic and genomic diversity of Lactobacillus plantarum strains isolated from various environmental niches. Environ Microbiol 12(3):758-773. https://doi.org/10.1111/j.14622920.2009.02119. $\mathrm{x}$

Simpson JT, Wong K, Jackman SD, Schein JE, Jones SJM, Birol I (2009) ABySS: a parallel assembler for short read sequence data. Genome Res 19(6):1117-1123. https://doi.org/10.1101/gr.089532.108

Smokvina T, Wels M, Polka J, Chervaux C, Brisse S, Boekhorst J, van Hylckama Vlieg JET, Siezen RJ (2013) Lactobacillus paracasei comparative genomics: towards species pan-genome definition and exploitation of diversity. PLoS One 8(7):e68731. https://doi.org/10. 1371/journal.pone.0068731

Sonowal R, Nandimath K, Kulkarni SS, Koushika SP, Nanjundiah V, Mahadevan S (2013) Hydrolysis of aromatic $\beta$-glucosides by nonpathogenic bacteria confers a chemical weapon against predators. Proc R Soc B 280:201307. https://doi.org/10.1098/rspb.2013.0721

Stamatakis A (2014) RAxML version 8: a tool for phylogenetic analysis and post-analysis of large phylogenies. Bioinformatics 30(9):13121313. https://doi.org/10.1093/bioinformatics/btu033

Sun Z, Harris HMB, McCann A, Guo C, Argimón S, Zhang W, Yang X, Jeffery IB, Cooney JC, Kagawa TF, Liu W, Song Y, Salvetti E, Wrobel A, Rasinkangas P, Parkhill J, Rea MC, O'Sullivan O, Ritari J, Douillard FP, Paul Ross R, Yang R, Briner AE, Felis GE, De Vos WM, Barrangou R, Klaenhammer TR, Caufield PW, Cui Y, Zhang H, O'Toole PW (2015) Expanding the biotechnology potential of lactobacilli through comparative genomics of 213 strains and associated genera. Nat Commun 6:8322. https://doi.org/10.1038/ ncomms 9322

Thierry A, Pogačić T, Weber M, Lortal S (2015) Production of flavor compounds by lactic acid bacteria in fermented foods. In: Mozzi F, Raya RR, Vignolo GM (eds) Biotechnology of lactic acid bacteria: novel applications, 2nd edn. Wiley-Blackwell, West Sussex, UK, pp 314-340

Warnes GR, Bolker B, Bonebakker L, Gentleman R, Liaw WHA, Lumley T, Maechler M, Magnusson A, Moeller S, Schwartz M, Venables B (2016) Various R programming tools for plotting data: gplots. R package version 3.0.1. https://CRAN.R-project.org/ package $=$ gplots

Whitley E, Ball J (2002) Statistics review 6: nonparametric methods. Crit Care 6:509-513. https://doi.org/10.1186/cc1820

Wu C, Huang J, Zhou R (2017) Genomics of lactic acid bacteria: current status and potential applications. Crit Rev Microbiol 43(4):393-404. https://doi.org/10.1080/1040841X.2016.1179623

Zhang W, Sun Z, Wu R, Meng H, Zhang H (2013) Comparative genome analysis of probiotic Lactobacillus casei Zhang. In: iconcept Press (ed) Genomics II-bacteria, viruses and metabolic pathways. Brisbane, pp 276-296

Zhang W, Zhang H (2014) Genomics of lactic acid bacteria. In: Zhang H, Cai Y (eds) Lactic acid bacteria: fundamentals and practice. Springer Netherlands, Dordrecht, pp 205-247

Zhang ZG, Ye ZQ, Yu L, Shi P (2011) Phylogenomic reconstruction of lactic acid bacteria: an update. BMC Evol Biol 11(1):1-12. https:// doi.org/10.1186/1471-2148-11-1

Zhao S, Guo Y, Sheng Q, Shyr Y (2015) An improved heatmap package: heatmap3. R package version 1.1.1. https://CRAN.R-project.org/ package $=$ heatmap3

Zheng J, Ruan L, Sun M, Gänzle M (2015) A genomic view of lactobacilli and pediococci demonstrates that phylogeny matches ecology and physiology. Appl Environ Microbiol 81(20):72337243. https://doi.org/10.1128/AEM.02116-15 